\title{
Leakage Evaluation of Three Endodontic Sealers Used in a Single- cone Technique: A Study Using Bioluminescent Bacteria
}

Sean M. Horan

Follow this and additional works at: https://researchrepository.wvu.edu/etd

\section{Recommended Citation}

Horan, Sean M., "Leakage Evaluation of Three Endodontic Sealers Used in a Single-cone Technique: A Study Using Bioluminescent Bacteria" (2017). Graduate Theses, Dissertations, and Problem Reports.

5822.

https://researchrepository.wvu.edu/etd/5822

This Thesis is protected by copyright and/or related rights. It has been brought to you by the The Research Repository @ WVU with permission from the rights-holder(s). You are free to use this Thesis in any way that is permitted by the copyright and related rights legislation that applies to your use. For other uses you must obtain permission from the rights-holder(s) directly, unless additional rights are indicated by a Creative Commons license in the record and/ or on the work itself. This Thesis has been accepted for inclusion in WVU Graduate Theses, Dissertations, and Problem Reports collection by an authorized administrator of The Research Repository @ WVU. For more information, please contact researchrepository@mail.wvu.edu. 


\title{
Leakage Evaluation of Three Endodontic Sealers Used in a Single-cone Technique: A Study Using Bioluminescent Bacteria
}

\author{
Sean M. Horan, D.D.S. \\ Thesis submitted to the School of Dentistry at West Virginia University \\ In partial fulfillment of the requirements for the degree of \\ Master of Science \\ In \\ Endodontics
}

Elizabeth C. Kao, D.M.D., Chair

L. Keith Hildebrand, D.D.S., M.S.

Bryan Weaver, D.D.S., M.D.

Jerry E. Bouquot, D.D.S., M.S.D.

Department of Endodontics

Morgantown, West Virginia

2017

Keywords: Dental, Endodontics, Single-Cone Obturation, Coronal Leakage, Sealer, Bioluminescent Bacteria

Copyright 2017 Sean M. Horan, D.D.S. 


\title{
$\underline{\text { Abstract }}$ \\ Leakage Evaluation of Three Endodontic Sealers Used in a Single-cone Technique: A Study Using Bioluminescent Bacteria
}

\author{
Sean M. Horan, D.D.S.
}

\section{Introduction}

After proper chemomechanical disinfection and obturation of a root canal system, the next important goal in endodontic therapy is obtaining an adequate coronal seal. If the coronal seal becomes compromised, it is difficult to decide whether the root canal system should be retreated. This decision should be made based on the ability of the root canal filling to resist bacterial contamination and on the length of time the seal has been compromised.

The root canal system should be filled in three dimensions, typically with a combination of gutta percha and sealer. One obturation method that has seen a revival in recent years is the single-cone technique. Newly developed sealers claim to create an effective seal through adhesive bonding to the gutta percha and/or dentin. The objective of this study was to evaluate the sealing ability of three currently available endodontic sealers used in a single-cone technique with a bacterial leakage model. A pilot study was also conducted in an attempt to better quantify and localize the bacteria in the obturated experimental teeth.

\section{Materials and Methods}

Fifty extracted human maxillary anterior teeth were decoronated and root length was standardized. Each tooth was instrumented and irrigated. The teeth were randomly divided into three experimental groups ( $n=12)$ and two control groups (5 positive and 5 negative). The final four teeth were used in the pilot study. Obturation of the three experimental groups, EndoSequence BC Sealer, ThermaSeal Plus Ribbon Sealer, or GuttaFlow 2, was performed with a single-cone technique using a ProTaper master cone. A bacterial leakage experimental apparatus was constructed to evaluate the seal created by each of the experimental groups.

For the pilot study, four teeth were obturated with varying levels of gutta percha and evaluated in the same experimental apparatus. A solution of a bioluminescent bacterium, Staphylococcus aureus Xen36, was used to inoculate each tooth. Scans of the teeth were taken with an In Vivo Imaging System (IVIS) at Days 0, 3, 7, and 10 to show whether bacteria could be detected at varying levels in the teeth.

The remaining forty-six apparatuses were evaluated with a more traditional bacterial leakage method, where Difco Purple Broth Base was placed in the lower chamber of the apparatus so that $2 \mathrm{~mm}$ of the root end was submerged. A solution of $S$. aureus Xen36 was used to inoculate the top chamber of the apparatus, and the apparatuses were incubated for up to 50 days. The apparatuses were checked daily to monitor for bacterial contamination.

\section{Results and Conclusion}

The pilot study was unable to provide accurate information on the localization and quantification of bacteria in the four sample teeth. For the traditional bacterial leakage study, 
each of the experimental groups had a noticeable amount of early leakage, and after one week, all three groups had a survival rate of 58.3\%. After 50 days, the ThermaSeal Plus Ribbon Sealer group had a survival rate of 8.3\%, while the EndoSequence BC Sealer and GuttaFlow 2 groups had a survival rate of $25.0 \%$. The log-rank test showed no statistically significant differences between the three groups with respect to leakage over time $(p=0.665)$. The results of the present study showed that in the absence of a coronal seal, the single-cone method of root canal obturation does not provide long-term sealing ability in many teeth. Further studies should be piloted to see if the IVIS could be beneficial for analyzing obturated teeth. 


\section{Dedication}

To my wife, MacKenzie: Thank you for all of your love and support. I feel fortunate that we have been able to go through our residencies at the same time. It has been stressful at times (we survived BioStatistics), but I would not have wanted it any other way. I can't wait to see what's in store for the next chapter of our lives. I love you.

To my parents, Tom and Mary Ann: Thank you for always pushing me to do my best and for encouraging me to pursue my interests and dreams. I would not be the person I am today without both of you.

To my in-laws, Glenn and Laura: Thank you for the constant support and advice you provide MacKenzie and me. I feel very lucky to be able to rely on your years of dental knowledge as we begin the transition into our professions. 


\section{Acknowledgements}

AAE Foundation/Dentsply - Thank you for your generosity in awarding the West Virginia University School of Dentistry Endodontic Department an Innovation in Research Grant (Fund \#2R388) which helped fund this research project.

Dr. M. Leigh Speer - Thank you for your mentorship over the past two and a half years. Your vast experience has been extremely helpful in developing my clinical skills as an endodontist.

Dr. L. Keith Hildebrand - Thank you for having an open mind and for being a great advocate for our program. Your experience has helped us out immensely.

Dr. A. Tom Borgia - I would not have begun this journey to become an endodontist if it weren't for you. Your enthusiasm and teaching abilities helped spark my interests as a student. Thank you for encouraging me to apply and for helping along the way.

Dr. Elizabeth Kao - Thank you for serving as chair of my committee. Your background with dental research has provided suggestions and recommendations to help me through the process.

Dr. Bryan Weaver - Thank you for being a last-minute addition to my committee! I am grateful for what you have taught us regarding the management of medically compromised patients through your advanced oral surgery class and through clinical consultations.

Dr. Jerry Bouquot - Thank you for your guidance with the research process. I have always enjoyed our conversations and appreciated your insight.

Mr. Chris Waters - Thank you for all of your assistance and advice with my project. Your help with the research process has been greatly appreciated. Thanks for the help with the protocol for the bacterial portion of my project and for letting me borrow some tools to make my apparatuses!

Ms. Sarah McLaughlin and Dr. Karen Martin - Thank you for the training and advice with the IVIS imaging part of my study.

Mr. Taron Dick and West Virginia Clinical and Translational Science Institute (WVCTSI) Thank you for all of your help with the statistics.

Dr. Jabeen Noore and WVU Orthopaedics - Thank you for providing the bacteria for my project and instructions for growth and preparation.

Mr. Damon Linear - Thank you for your help and accommodations with the sterilization of my project apparatuses.

Dr. Stephen Fragale - You have been the best co-resident I could've asked for. It has been great being able to bounce ideas off each other to help each other become better clinicians. We have endured a lot of change over the past 2.5 years, but it has helped having a fellow West Virginian 
and WVU Dental grad alongside. I look forward to future endo meetings and golfing adventures. I'm happy you will finally get to be with Amanda full-time in Charleston!

Dr. Emma Hunter - I was amazed how you were able to manage three kids and exercise consistently during all the stresses of residency. I appreciated your advice while I was a first year and was glad you were able to have thick skin at times being the only female in the endo resident room!

Dr. Wisam Sakr - Thank you for your encouragement while I was a first year. I continue to be on the lookout for three-canal premolars because of your case presentations!

Dr. Michael Tran - I have appreciated learning some new tricks from you. Your dedication to strive for the best has been great to see. Don't let those micro accesses prevent you from finding MB2! I look forward to eventually hitting the links with you when I find myself in Cali!

Dr. Travis Moore - You have progressed a lot as a clinician in the past year. I admire your ability to be adventurous with trying new materials and techniques. Good luck with your final year and beyond!

Dr. Mehran Malakpour - I have never seen someone so dedicated and interested in endo from such an early point in his or her dental career. It has been enjoyable seeing you transition from student to endo resident!

Dr. Cade Brawley - Thanks for bringing some Texas flair to the program! I have enjoyed talking about endo cases and football with you. I look forward to tailgating with you in Lubbock sometime once we're all out practicing! 


\section{Table of Contents}

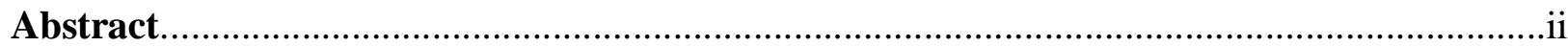

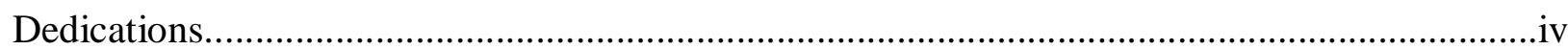

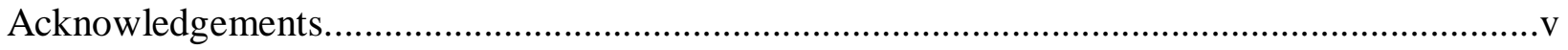

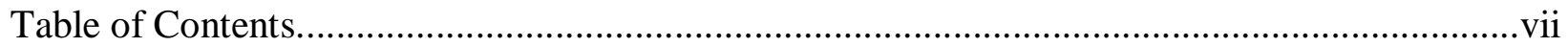

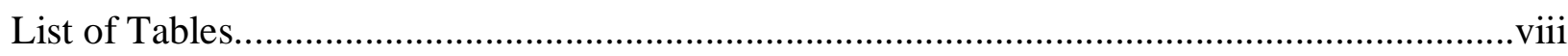

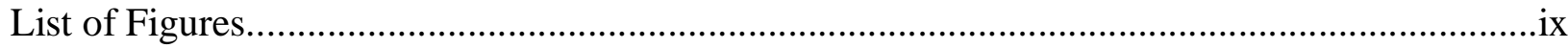

List of Symbols, Abbreviation, or Nomenclature..........................................

\section{Chapter 1}

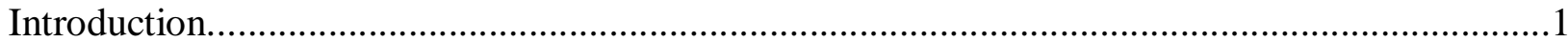

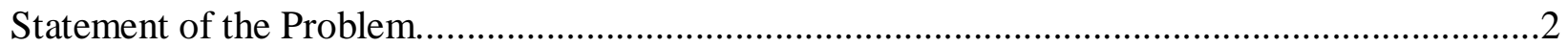

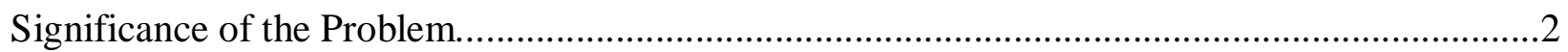

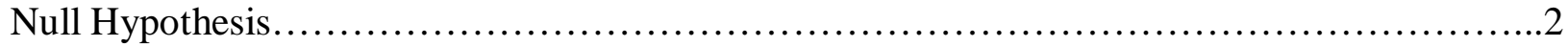

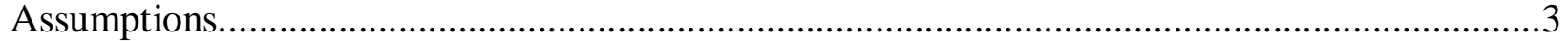

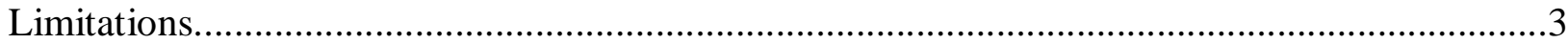

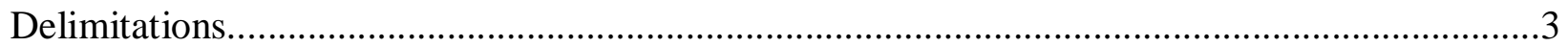

\section{Chapter 2}

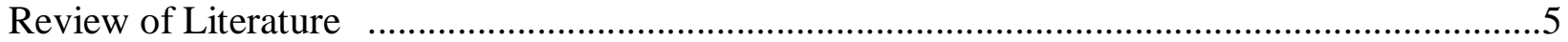

\section{Chapter 3}

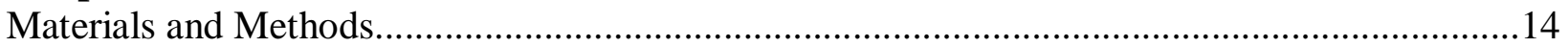

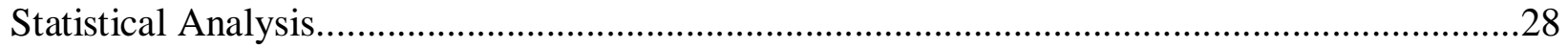

\section{Chapter 4}

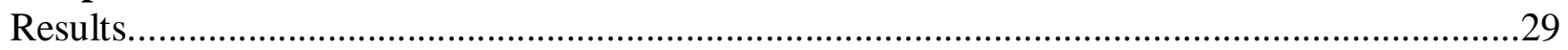

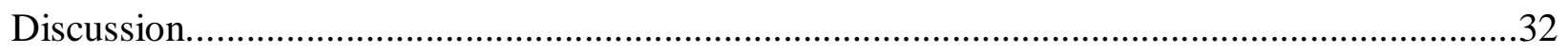

\section{Chapter 5}

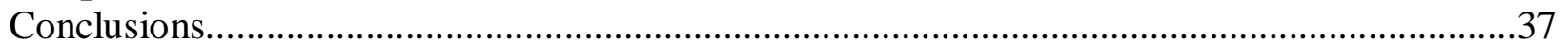

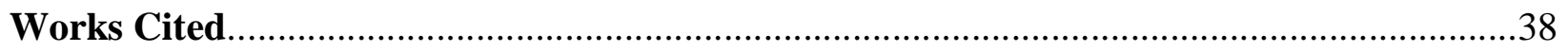

\section{Appendix}

Data Collection for Statistical Analysis.............................................44 


\section{$\underline{\text { List of Tables }}$}

Table 1: Survival rates of the three experimental groups at different observation times..........31 


\section{List of Figures}

Figure 1: Selection of various brands of greater taper gutta percha.........................6

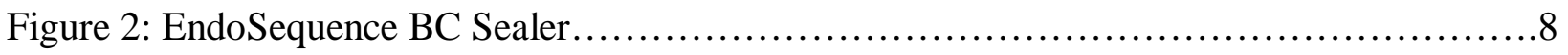

Figure 3: ThermaSeal Plus Ribbon Sealer............................................

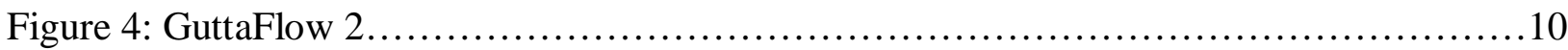

Figure 5: Detection limits of the bioluminescent bacteria used in Sedgley's study...............12

Figure 6: Second sub-culture of Staphylococcus aureus Xen36 used to create stock solutions...16

Figure $7: 15 \mathrm{ml}$ microcentrifuge tubes labeled with each of the stock solutions.................16

Figure 8: LB broth used for bacterial growth in stock solutions.............................17

Figure 9: Machine used to vortex stock bacterial solutions................................17

Figure 10: Densitometer used to perform McFarland test on stock bacterial solutions...........18

Figure 11: L-Spreaders used to evenly distribute bacterial solution on BAP...................19

Figure 12: Sample BAP with even distribution of bacterial growth..........................19

Figure 13: Sample of decoronated maxillary anterior teeth (side and incisal views).............21

Figure 14: Dental operating microscope used for instrumentation and obturation of samples....21

Figure 15: Sequence of hand files and ProTaper Universal rotary files used....................22

Figure 16: Irrigating solutions and sample irrigation syringe and tip used.....................22

Figure 17: Final ProTaper Universal file used and corresponding gutta percha points...........23

Figure 18: Elements Free downpack unit.................................................24

Figure 19: In Vivo Imaging System (IVIS) linked to data-acquisition computer................26

Figure 20: Difco Purple Broth Base with 1\% D-Fructose carbohydrate.........................27

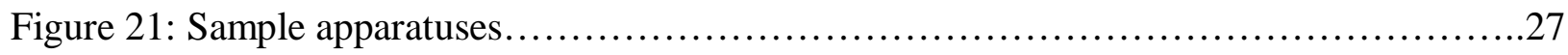

Figure 22: Storage of samples, stock solutions, and BAPs in incubator at $37^{\circ} \mathrm{C} \ldots \ldots \ldots \ldots \ldots \ldots .28$ 
Figure 23: Bioluminescence produced by $S$. aureus Xen36 at 7 days........................29

Figure 24: Bioluminescence produced by S. aureus Xen36 at 10 days.........................30

Figure 25: Survival rates over the 50 -day observation period..............................31 


\section{List of Symbols, Abbreviation, or Nomenclature}

Blood Agar Plate - BAP - a Petri dish containing mammalian blood used to culture microorganisms.

Colony forming units per milliliter - Cfu/ml - a unit used to estimate the number of viable bacterial cells in a sample solution.

In Vivo Imaging System - IVIS - an optical imaging device that uses filters and algorithms to recognize bioluminescent and fluorescent reporters in bacteria.

Luria-Bertani broth - LB broth - a nutritionally rich medium used for bacterial growth.

McFarland - a set of standards used as a reference of the turbidity of a bacterial suspension. A densitometer is used to test the McFarland rating of the suspension.

Mineral Trioxide Aggregate - MTA - a calcium silicate dental material often used for root repair.

Root Canal System - RCS - the space containing the dental pulp inside the crown and root of a tooth.

Vortex - a device which produces a spinning, often turbulent, flow of liquid.

Working Length - WL - the distance from a coronal reference point to the point at which canal preparation and obturation should terminate. 


\section{Chapter 1}

\section{Introduction}

Obtaining an adequate coronal seal is of utmost importance following completion of root canal therapy. ${ }^{1-3}$ However, if the coronal seal becomes compromised, re-contamination of the obturated root canal system (RCS) can occur. The seal can become compromised if there is an extensive delay in the placement of definitive restorations, if definitive or provisional restorations lack marginal integrity, if the tooth becomes fractured, or if recurrent decay develops and exposes the endodontic filling material. ${ }^{4,5}$ If one of these instances occurs and the coronal portion of endodontic filling is exposed to oral bacteria, it is often difficult to decide the best plan of action. The decision to retreat the RCS should be based on the length of time it takes the entire length of the RCS to become contaminated after loss of coronal seal. Bacterial leakage has been supported as the most clinically relevant model for evaluation of the seal provided by endodontic filling materials. ${ }^{6}$

To better resist re-contamination, the RCS should optimally be filled in three dimensions after proper debridement. ${ }^{7}$ Gutta percha is the most widely used root canal filling, and many methods of its utilization have been employed. One method that has seen a revival in recent years is the single-cone technique. ${ }^{8}$ In the past, this technique has been thought to be less effective in sealing than cold lateral condensation or warm vertical condensation techniques; however, the introduction of new sealers and greater taper master cones may support the use of the single-cone technique.

In this study, three contemporary endodontic sealers that have the ability to be used in a single-cone technique were analyzed in a bacterial leakage model to determine the length of time required for full contamination of the RCS. Additionally, a pilot study utilizing an In Vivo 
Imaging System (IVIS) was conducted in an attempt to better localize and quantify the bacteria in the sample teeth.

\section{Statement of the Problem}

Can newly developed sealers provide resistance or delay full bacterial re-contamination in root canal systems obturated with the single-cone technique?

\section{Significance of the Problem}

With the advent of new endodontic sealers, many dental schools are beginning to change their endodontic teaching philosophy. Some schools are starting to exclusively teach single-cone methods of obturation to their undergraduate dental students and post-graduate endodontic residents. Although this appears to simplify the process of endodontic obturation, students may not understand its indications and limitations. As the single-cone technique becomes increasingly popular and prevalent, practitioners should have some guidelines for the management of a lost coronal seal. This study will provide information on the sealing ability of new sealers recommended for use in the single-cone technique and offer some guidelines for treatment in the event where the coronal seal has been lost.

\section{Null Hypothesis}

There is no significant difference in bacterial leakage over time for the three endodontic sealers tested: EndoSequence BC Sealer (Brasseler USA, Savannah, GA), ThermaSeal Plus Ribbon Sealer (Dentsply Tulsa Dental Specialties, Tulsa, OK), and GuttaFlow 2 (Coltene/Whaledent Inc., Cuyahoga Falls, OH). 


\section{Assumptions}

1. A bacterial leakage model is a reliable, scientific way to assess the seal of a root canal filling.

2. When the color of the broth in the experimental apparatuses changes from purple to yellow, full bacterial contamination of the RCS has occurred.

\section{$\underline{\text { Limitations }}$}

1. The canals of the experimental teeth have varying degrees of irregularity in their internal anatomy.

2. The oral flora that can re-contaminate a RCS are extremely diverse, but only a single species was used in this study.

3. This is an in vitro experiment that does not fully capture the in vivo environment and reaction process.

4. Human error may have been involved in the techniques.

5. Sample size of prepared and obturated teeth is small.

\section{$\underline{\text { Delimitations }}$}

1. An effort was made to limit the teeth to maxillary anteriors with straight roots and canals with relatively round cross-sections.

2. Only roots with completely formed apices and no visible caries/resorption were selected.

3. Crowns were sectioned and the roots were standardized to an approximate length of 16 $\mathrm{mm}$. 
4. Teeth where no cutting was evident on the tip of the F4 file (large apical diameter canals) were excluded.

5. Gutta percha was removed to a level that allowed approximately $14 \mathrm{~mm}$ to remain, taking working length (WL) into account.

6. A dental operating microscope (Global Surgical Corporation, St. Louis, MO) was used at 6.4x magnification for $\mathrm{WL}$ determination, instrumentation, and obturation.

7. All samples were prepared by a single operator (the principal investigator). 


\section{Chapter 2}

\section{$\underline{\text { Review of Literature }}$}

The primary cause of apical periodontitis is the presence of microorganisms in a RCS. ${ }^{9,10}$ Proper endodontic treatment involves chemomechanical methods for the reduction of the microbial load in this system. ${ }^{11}$ Mechanical debridement by hand and rotary instruments provides shape in the RCS. Common endodontic irrigants such as sodium hypochlorite ( $\mathrm{NaOCl})$ and ethylenediaminetetraacetic acid (EDTA) can then be used to penetrate the areas of the RCS that are mechanically inaccessible. ${ }^{12}$

After disinfection, the next goal of endodontic treatment is three-dimensionally filling this cleaned and shaped system to prevent re-infection. ${ }^{713}$ Wu and Wesselink stated, "The development and maintenance of a hermetic seal is considered to be a major prerequisite for success in root canal treatment”. ${ }^{14}$ Numerous techniques and materials have been accepted as ways of achieving this "hermetic seal." These techniques include sealer only, lateral compaction, warm vertical compaction, single-cone, and carrier-based techniques. ${ }^{15}$

In sealer only techniques, a cement or paste is placed to fill the entire RCS without the use of a gutta percha master cone. With lateral compaction, a master cone is selected based on the final file used and this cone is coated with a sealer and seated at the WL. A spreader is then introduced alongside to compress the master cone laterally. After removal of the spreader, accessory cones of gutta percha are placed to fill the void created by the spreader. This process is continued until a dense fill is achieved. For warm vertical compaction, a master cone is also selected and placed just as it would be with the lateral compaction technique. However, instead of adding accessory cones, the coronal portion of the master cone is melted with a heat source and the apical 3-5 mm of remaining gutta percha is condensed with pluggers. The space above 
this apical "plug" is then backfilled with warm injectable gutta percha. Carrier-based techniques utilize a plastic or harder gutta percha carrier that is coated in a softer gutta percha. After a light coating of sealer on the canal walls, an oven is used to soften the outer layer of gutta percha on the carrier. When soft, the carrier is placed in the canal to the WL. For the single-cone technique, sealer is used to coat the walls of the RCS, and a single master cone of gutta percha corresponding to the final file size is coated in the sealer and placed to WL.

Operators often debate these various techniques, but there is still little evidence to support or deny a particular technique. Whitworth stated, “As no single approach can unequivocally boast superior evidence of healing success, decisions may be based on such factors as speed, simplicity, economics, or 'how it feels in my hands'”. ${ }^{16}$ Previously, single-cone techniques performed with conventional sealers were thought to be less effective than other methods of condensation. ${ }^{17}$ However, the introduction of new sealers and greater taper master cones have provided a revival of the single-cone technique.

Greater taper master cones of gutta percha have been created by different companies to closely match the geometry of their nickel-titanium rotary instrumentation systems. ${ }^{18}$

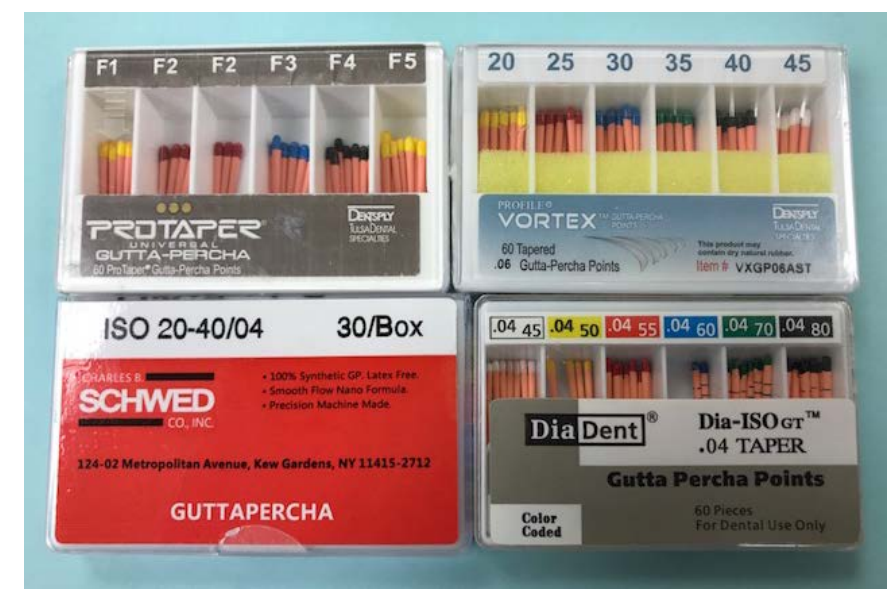

Figure 1: Selection of various brands of greater taper gutta percha. Some of these gutta percha cones have a variable taper (ProTaper), while others have standardized .04 or .06 tapers. 
This greatly reduces the space that sealer needs to occupy between the master cone and canal walls. However, root canal systems are not perfect cylinders, so the sealer used in conjunction with the master cone must have properties that enable sealing of the canal irregularities that could potentially harbor bacteria. New root canal sealers on the market claim to be able to create an adhesive bond along the sealer - gutta percha interface and/or along the sealer - dentin interface, reinforcing the viability of single-cone applications. ${ }^{19}$

Sagsen et al. said that there are certain characteristics that an ideal filling material must possess; these include adequate marginal sealing quality, biocompatibility, and the ability to allow or induce bone repair and antimicrobial activity. ${ }^{20}$ Since sealers may be placed in close contact with the periapical tissues, it is possible that the tissue response to the sealer could influence the outcome of root canal treatment. ${ }^{21}$ An operator should take the technique and the above listed properties into account when selecting a sealer for use. Currently available sealers include zinc oxide eugenol and non-eugenol sealers, calcium hydroxide sealers, glass ionomer sealers, epoxy resin-based sealers, silicone sealers, medicated sealers, and the more recently introduced methacrylate-resin-based sealers and calcium silicate-based sealers. ${ }^{22}$

EndoSequence BC Sealer (Brasseler USA, Savannah, GA) is a premixed bioceramic cement paste based on a calcium silicate composition that requires moisture for setting (Figure 2). It's manufacturer claims that it has excellent physical properties, exhibits no shrinkage, and forms hydroxyapatite upon setting to create a chemical bond with dentin. ${ }^{23,24}$ Testing of BC Sealer, also known as iRoot SP, has shown that it has antimicrobial activity ${ }^{25}$ and good sealing ability. ${ }^{26}$ A study of its cytotoxicity revealed slight toxicity with a fresh mix and no toxic effects after setting at 24 hours. It was significantly less cytotoxic than the resin sealer tested (AH Plus) and was comparable to another calcium silicate material, mineral trioxide aggregate (MTA). ${ }^{27}$ 


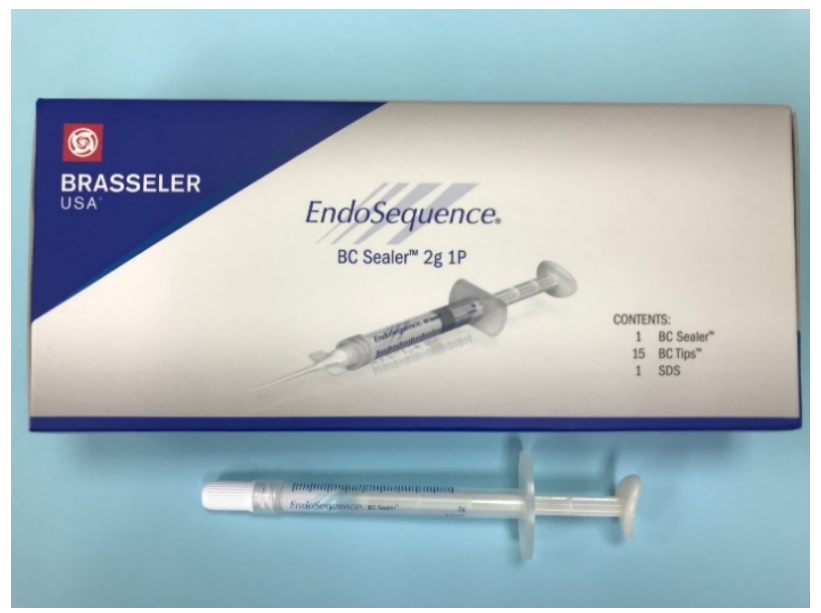

Figure 2: A bioceramic cement paste. EndoSequence BC Sealer packaging and syringe.

ThermaSeal Plus Ribbon Sealer (Dentsply Tulsa Dental Specialties, Tulsa, OK) is a twocomponent paste based on epoxy-amine resin that has long-term sealing and self-adhesive properties. $^{28}$ It comes in a mixing syringe to provide a convenient, precise mixture (Figure 3). A study by Pinna et al. showed that AH Plus (another name for ThermaSeal Plus) did not have the long-term cytotoxic effects that Pulp Canal Sealer (SybronEndo) possessed. ${ }^{29}$ Although good in the long-term, moderate to severe cytotoxicity was still present for the first week after mixing. This is likely due to the epoxy resin component of the sealer that is released after setting. ${ }^{30}$ The sealer's adhesive properties and adaptability to the root canal walls have been cited as reasons for its excellent sealing abilities and resistance to bacterial coronal leakage. ${ }^{31}$ 


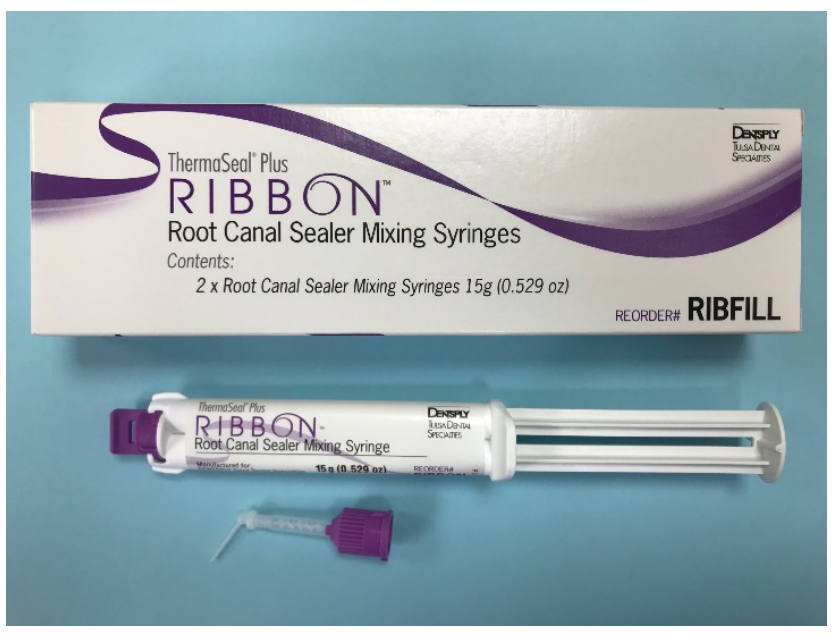

Figure 3: An epoxy-amine resin paste. ThermaSeal Plus Ribbon Sealer packaging, syringe, and dispensing tip.

GuttaFlow 2 (Coltene/Whaledent Inc., Cuyahoga Falls, OH) is a novel filling system that combines finely ground gutta percha powder with a polydimethylsiloxane matrix (Figure 4). It has very good adhesion to both gutta percha and dentin and expands slightly (0.2\%) to provide an excellent seal. ${ }^{32}$ It has been shown to have excellent biocompatibility, similar to mineral trioxide aggregate (MTA), with less cytotoxic response to human gingival fibroblast cells when compared to AH Plus and RealSeal (SybronEndo). ${ }^{33}$ The manufacturers of GuttaFlow 2, EndoSequence BC sealer, and ThermaSeal Plus Ribbon Sealer all advocate that these sealers can be used in a single-cone technique. ${ }^{24,28,32}$ 


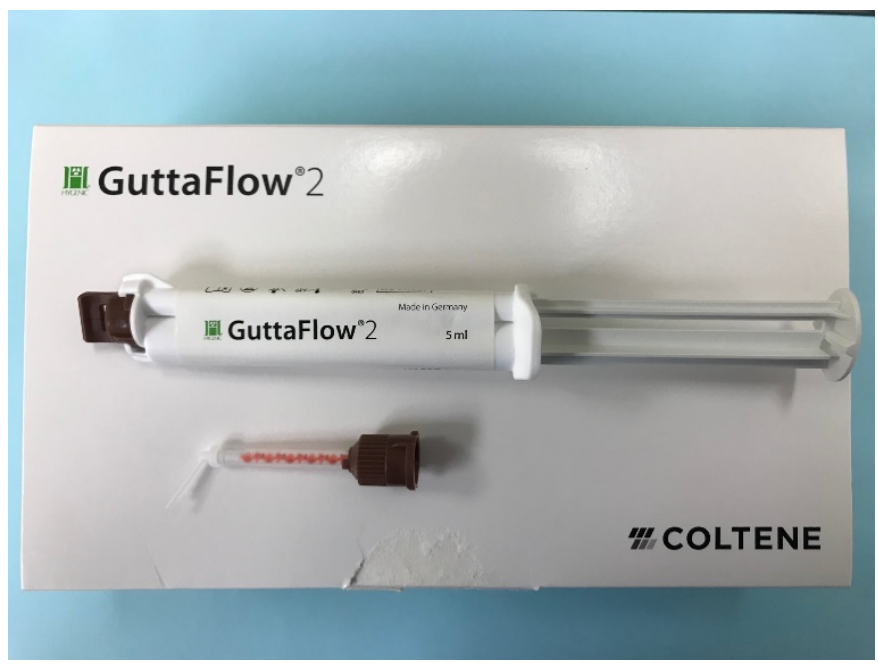

Figure 4: A polydimethylsiloxane paste with finely ground gutta percha powder. GuttaFlow 2 packaging, syringe, and dispensing tip.

After obturation of the RCS, the next major goal of endodontic treatment is sealing the crown of the tooth to prevent future recontamination of the sealed root canals. ${ }^{4}$ This is a critical, often under-valued component to proper endodontic treatment. Research reported by Ray and Trope in 1995 showed that the quality of the coronal restoration had more impact on the presence of periapical inflammation than quality of the root filling. ${ }^{34}$ These findings make it critical to restore the crown of the tooth as expeditiously as possible. ${ }^{35}$ If the tooth cannot be restored immediately, a temporary filling material should be used to minimize possible leakage. The temporary restoration should be a minimum of four millimeters in thickness and should not be expected to last more than three weeks. ${ }^{4}$

If the patient delays having a permanent restoration placed, if a restoration is lost or its integrity becomes compromised, or if the root canal filling material is exposed through tooth fracture or recurrent decay, the complication of re-contamination of the RCS arises. ${ }^{4,5}$ When one of these instances occur and the coronal portion of the RCS is exposed to oral flora, it is difficult to decide whether retreatment of the root canal is necessary. This decision should be 
made based on the length of time it takes for the entire root canal system to become contaminated. Previous in-vitro studies have used fluid filtration ${ }^{36,37}$ and dye leakage ${ }^{1-3}$ to evaluate the seal of endodontic materials, but bacterial leakage has been shown to be a more clinically relevant model. ${ }^{6}$ Bacterial penetration studies have utilized a multitude of singular species $^{38-40}$ or fresh human saliva. ${ }^{5,41,42}$

An in-vitro bacterial leakage model has been utilized to evaluate the leakage of numerous sealers and obturation techniques. ${ }^{5,39,40}$ The model consists of a split-chamber, with the obturated tooth connecting the two spaces. If bacteria are introduced to the top chamber, the only way they can reach the bottom chamber is through the tooth. To determine when bacterial contamination of the bottom chamber has occurred, the tip of the obturated tooth is submerged in a broth that can become turbid once contaminated with bacteria. A different type of media was utilized in Fransen's study, which made bacterial contamination more identifiable. In the model described in his study, the tip of the tooth was submerged in Difco Purple Broth Base (Beckton Dickinson, Sparks, MD). ${ }^{40}$ When supplemented with a carbohydrate, the Difco Purple Broth Base is able to elicit a fermentation reaction when bacteria are exposed to it. Acid is produced by the fermentation reaction, and as the $\mathrm{pH}$ of the broth drops below 6.8, the indicator changes from purple to yellow color. ${ }^{43}$ This color change provides a more distinct and abrupt determination of leakage compared to the assessment of turbidity. The bacterial leakage model, although effective in determining when full bacterial penetration of the canal has occurred, does not allow quantification or localization of the bacteria in the RCS. Being able to localize how far bacteria have penetrated into a RCS at different time points would be beneficial in determining the need for full retreatment. 
A potential way of quantifying and localizing bacteria in a RCS has been proposed by another author. ${ }^{44}$ This method involves using bioluminescent reporter bacteria that can be detected using an In Vivo Imaging System (IVIS). Bioluminescent reporters are constructed by fusion of a lux gene (responsible for the emission of visible light) with an inducible promoter. ${ }^{45}$ Bioluminescent bacteria have been used for real-time imaging of biofilms in mice, ${ }^{46}$ but their utilization in root canal studies has been minimal. ${ }^{44}$ A preliminary investigation by Sedgley was able to utilize bioluminescence imaging to study the effect of sequential irrigation procedures on the removal of bacteria from root canals. The study also analyzed different concentrations of bacteria to determine the limits of detection using such machinery and software (Figure 5). ${ }^{44}$
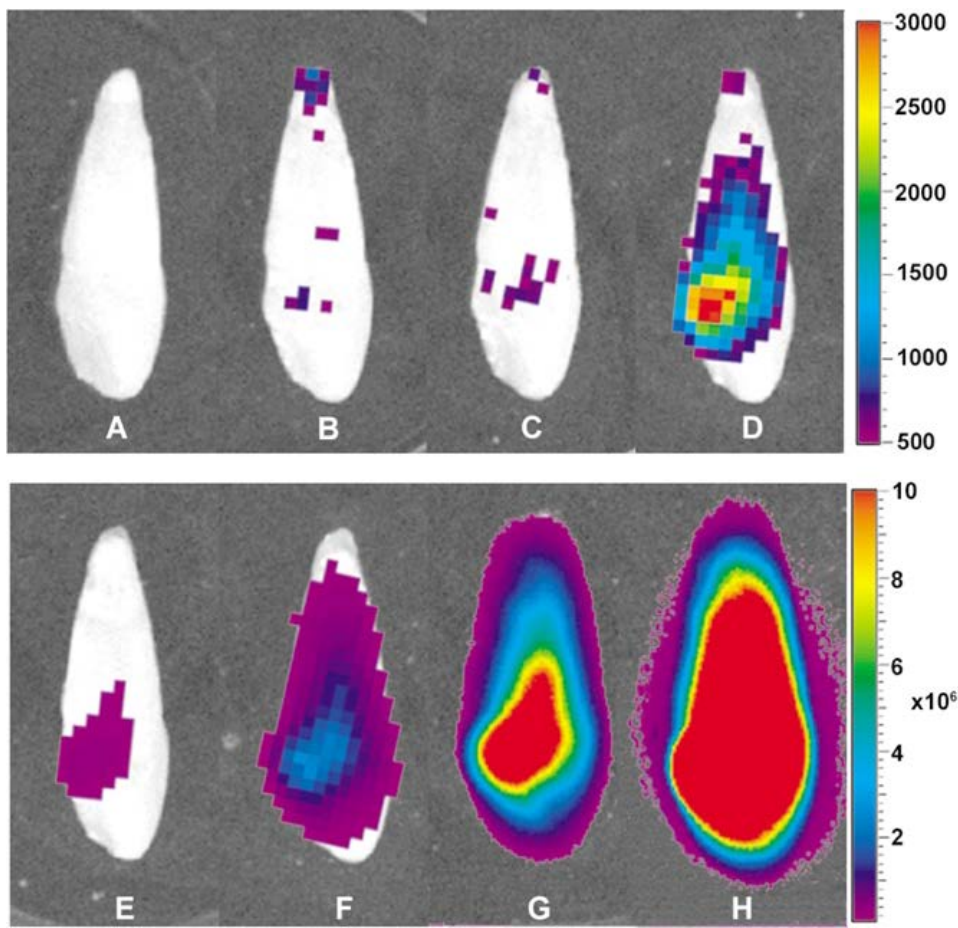

Figure 5: Detection limits of the bioluminescent bacteria P. fluorescens 5RL used in Sedgley's study. (A) No bacteria, (B) $2 \times 10$, (C) $2 \times 10^{2}$, (D) $2 \times 10^{3}$, (E) $2 \times 10^{4}$, (F) $2 \times 10^{5}$, (G) $2 \times 10^{6}$, (H) $2 \times 10^{7} .{ }^{44}$ 
It should be noted in the figure that the bioluminescent images in $\mathrm{G}$ and $\mathrm{H}$ are larger than the tooth. This is due to the photons being emitted in all directions from the bacteria. A clear outline of the root canal space would not be expected with this type of imaging. ${ }^{44}$

The bacterial population associated with failing endodontic cases has been shown to be different from that of primary necrotic cases. Gram-positive facultative anaerobes typically predominate failing endodontic cases, with Streptococcus, Enterococcus, Staphylococcus, Actinomyces, and Lactobacillus species being the most commonly isolated. ${ }^{47,48}$ Although Enterococcus faecalis is frequently isolated from re-treatment cases and used for the study of coronal leakage ${ }^{40}$ many other species have been used, including Streptococcus mutans ${ }^{39}$ and Staphylococcus epidermis. ${ }^{38}$ Staphylococci are non-motile, non-spore forming facultative anaerobes that grow by either fermentation or aerobic respiration. ${ }^{49}$ With these qualities, Staphylococci are able to survive in a coronally unsealed RCS. Staphylococcus aureus ATCC 49525 (Xen36) possesses these qualities as well as a lux gene, which allows it to emit bioluminescent light. ${ }^{50}$

Although Sedgley's study showed the ability of bioluminescence imaging to detect bacteria in root canal systems, literature showing the ability of this technique to detect bacteria in obturated canals is lacking. Therefore, the purpose of this experiment was twofold: to investigate the possibility of using bioluminescence imaging for the evaluation of bacterial leakage in obturated root canals, and to use an in vitro bacterial leakage model to evaluate the resistance to bacterial contamination of three endodontic sealers used with the single-cone technique. 


\section{Chapter 3}

\section{Materials and Methods}

\section{Bacteria}

Staphylococcus aureus Xen36 was the bacteria used in the experimental procedures of this study. Sedgley's study determined that the lower limit of bacterial detection in root canals by the IVIS is between $2 \times 10^{2}$ and $2 \times 10^{3} \mathrm{cfu} / \mathrm{mL}$. It was decided to use a concentration of bacteria of $1 \times 10^{6}$, which is similar to what was used in the experimental section of their study. The inoculum was prepared as follows:

A clinical isolate of Staphylococcus aureus Xen36 was obtained and fresh sub-cultures were grown on blood agar plates (BAP) (Thermo Scientific, Waltham, MA)(Figure 6). A stock solution was made from the 2 nd sub-culture. $15 \mathrm{ml}$ microcentrifuge tubes were labeled with the organism ID (Figure 7). The stock solutions were prepared as follows:

1st tube $-(4.0$ McFarland Test $)=\mathbf{1 0}^{\mathbf{9}} \mathrm{cfu} / \mathrm{ml}$.

- 10ml Luria-Bertani (LB) broth (Figure 8) was placed in tube 1.

- A 10ul lambda loop was used to scoop bacteria from the BAP.

- The lambda loop with bacteria was placed into the $10 \mathrm{ml}$ of LB broth.

- Spun lambda loop with bacteria to disperse bacteria into media.

- Vortexed the solution (Figure 9).

- Incubated the stock solution for $20-24$ hours at $37^{\circ} \mathrm{C}$.

- Vortexed the solution.

- McFarland Test was performed to verify concentration of solution (Figure 10). 
$10^{8}$ and $10^{6} \mathrm{cfu} / \mathrm{ml}$ dilutions were then prepared from the stock solution of $10^{9} \mathrm{cfu} / \mathrm{ml}$.

2nd tube $\mathbf{1 0}^{\mathbf{8}}$ - Dilution Calculation: $\left(10^{8}\right)(10 \mathrm{ml})=\left(10^{9}\right)(\mathrm{x})$

$$
\begin{aligned}
& \mathbf{x}=\mathbf{1 . 0} \mathbf{m l} \text { of } 10^{9} \text { Stock }+\mathbf{9 . 0 0} \mathbf{m l} \text { of LB broth } \\
& 1 / 10 \text { dilution }
\end{aligned}
$$

- 10ml of LB broth was placed in tube 2, and $1.0 \mathrm{ml}$ from the tube was removed with a micropipette and discarded.

- 1.0ml of the stock solution in tube $1\left(10^{9}\right)$ was added into tube $2\left(10^{8}\right)$.

- Vortexed the solution.

- McFarland Test was performed to verify concentration of solution.

3rd tube $10^{6}$ - Dilution Calculation: $\left(10^{6}\right)(10 \mathrm{ml})=\left(10^{8}\right)(\mathrm{x})$

$$
\begin{aligned}
& \mathbf{x}=\mathbf{0 . 1} \mathbf{m l}(\mathbf{1 0 0 u l}) \text { of } 10^{8} \text { stock }+\mathbf{9 . 9 0} \mathbf{m l} \text { of LB broth } \\
& 0.1 / 10=1 / 100 \text { dilution }
\end{aligned}
$$

- 10ml of LB broth was placed in tube 3, and $\mathbf{1 0 0 u l}(\mathbf{0 . 1} \mathbf{m l})$ from the tube was removed with a micropipette and discarded.

- 100ul (0.1ml) of the solution in tube $2\left(10^{8}\right)$ was added into tube $3\left(10^{6}\right)$.

- Vortexed the solution.

- McFarland Test was performed to verify concentration of solution. 


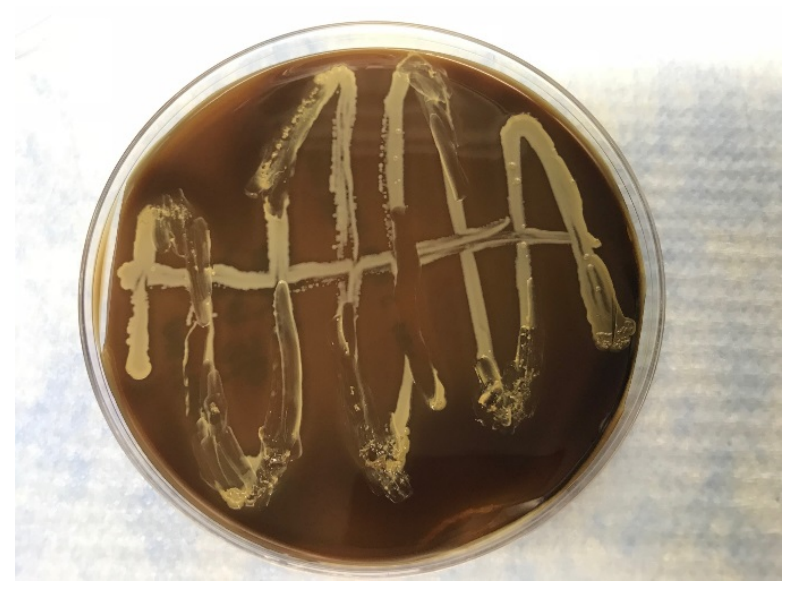

Figure 6: Second sub-culture of Staphylococcus aureus Xen36 used to create stock solutions.

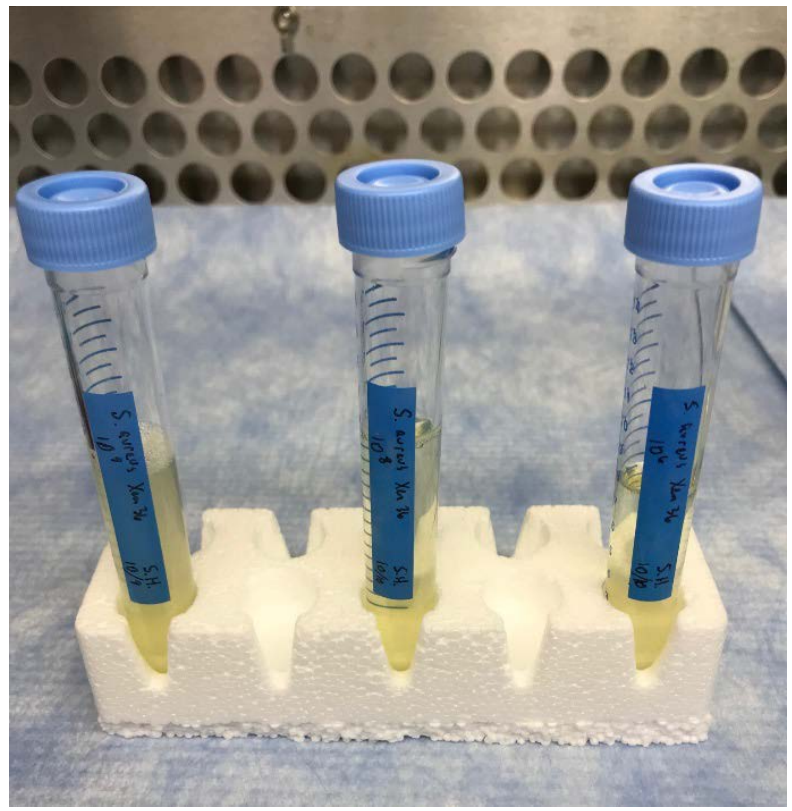

Figure 7: $15 \mathrm{ml}$ microcentrifuge tubes labeled with each of the stock solutions $\left(10^{9}, 10^{8}, 10^{6}\right)$. 


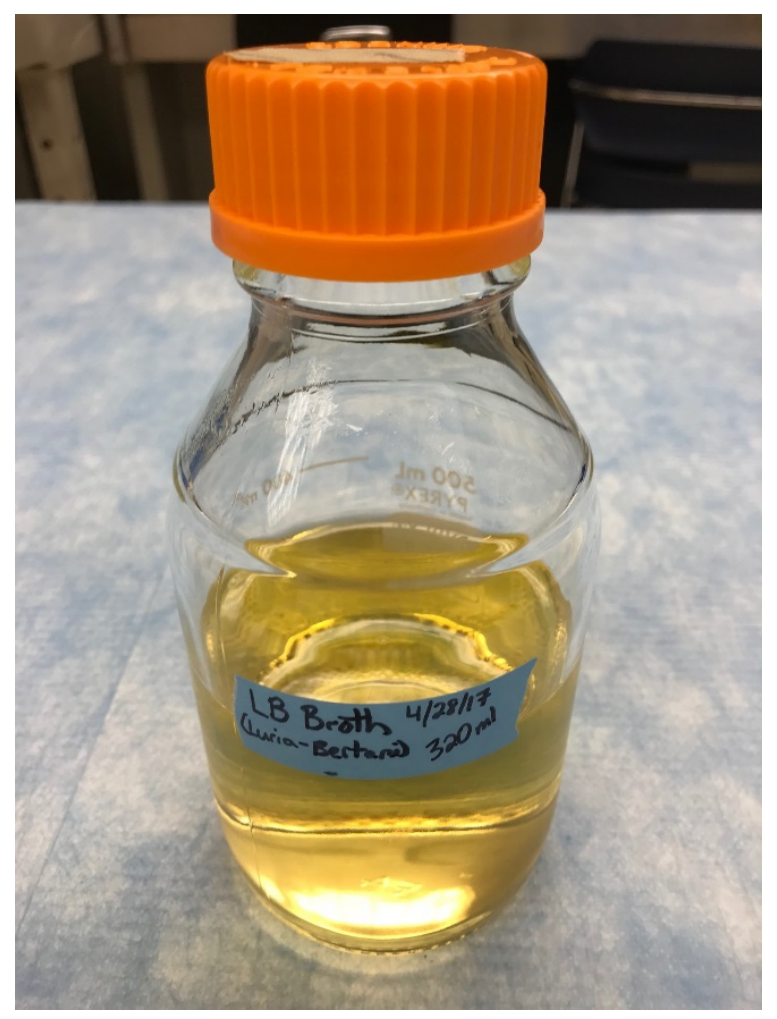

Figure 8: LB broth used for bacterial growth in stock solutions.

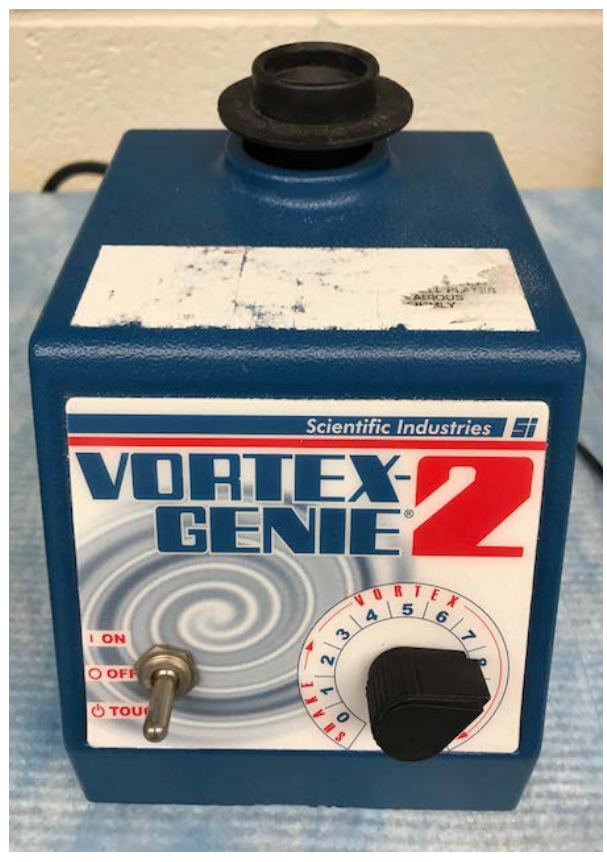

Figure 9: Machine used to vortex stock bacterial solutions. 


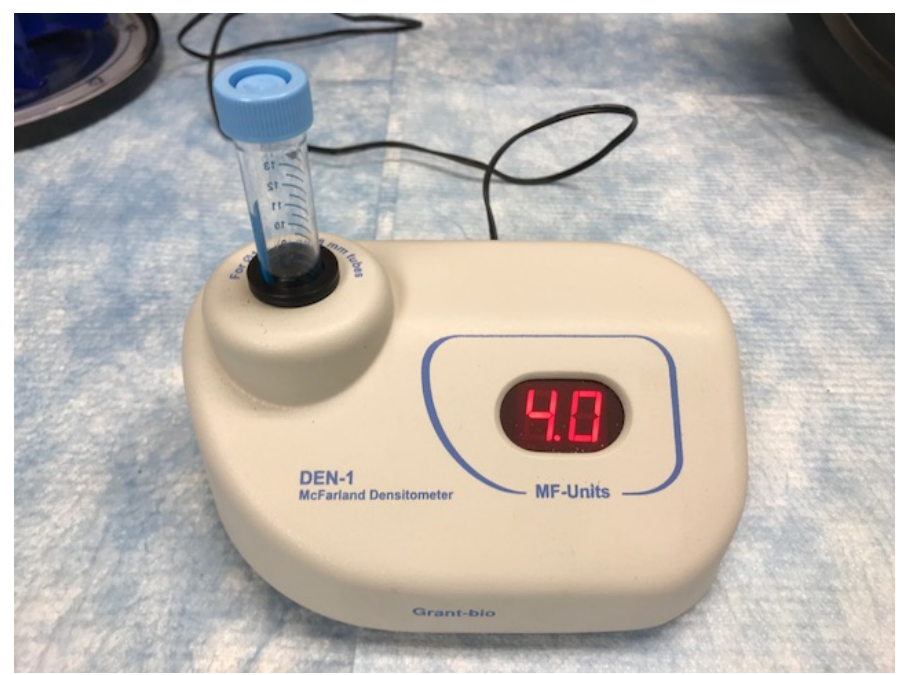

Figure 10: Densitometer used to perform McFarland test on stock bacterial solutions.

Growth was verified the following way:

A sterile pipette was used to remove $\mathbf{0 . 5 m l}(\mathbf{5 0 0 u l})$ of the bacterial organism $\left(10^{6}\right)$ from dilution tube 3, and this was placed onto the center of 1 BAP (Blood Agar Plate), properly labeled and dated. Using an L-Spreader (Figure 11), the sample solution was spread circularly around the BAP to give a nice even distribution of sample growth. The sample was placed into a $37^{\circ} \mathrm{C}$ incubator and removed when sample growth was adequate (Figure 12). Growth was scored to ensure viability of the sample. 


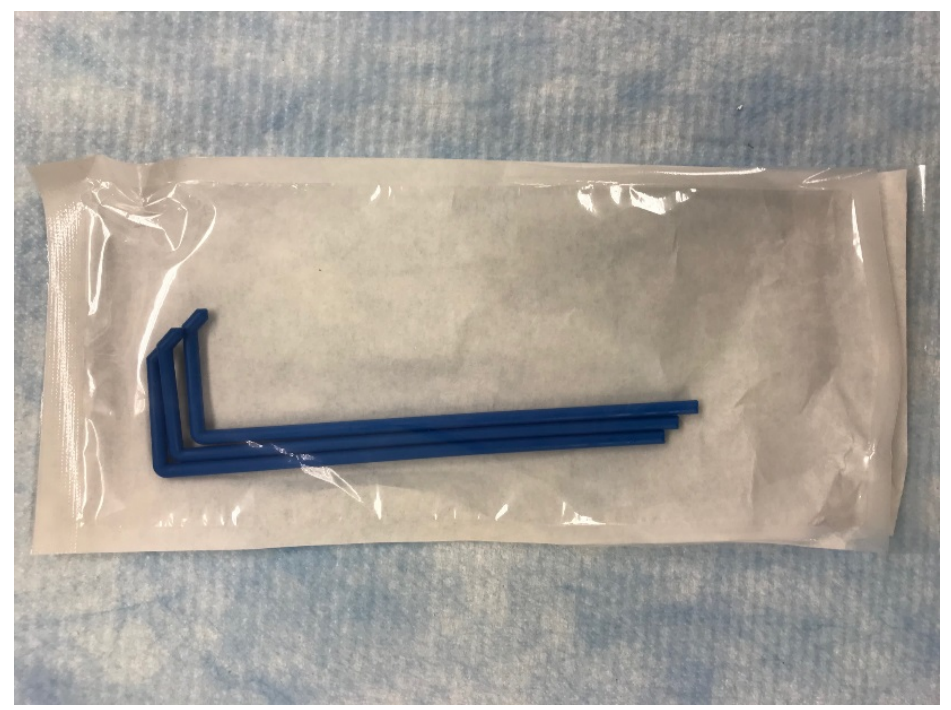

Figure 11: L-Spreaders used to evenly distribute bacterial solution on BAP.

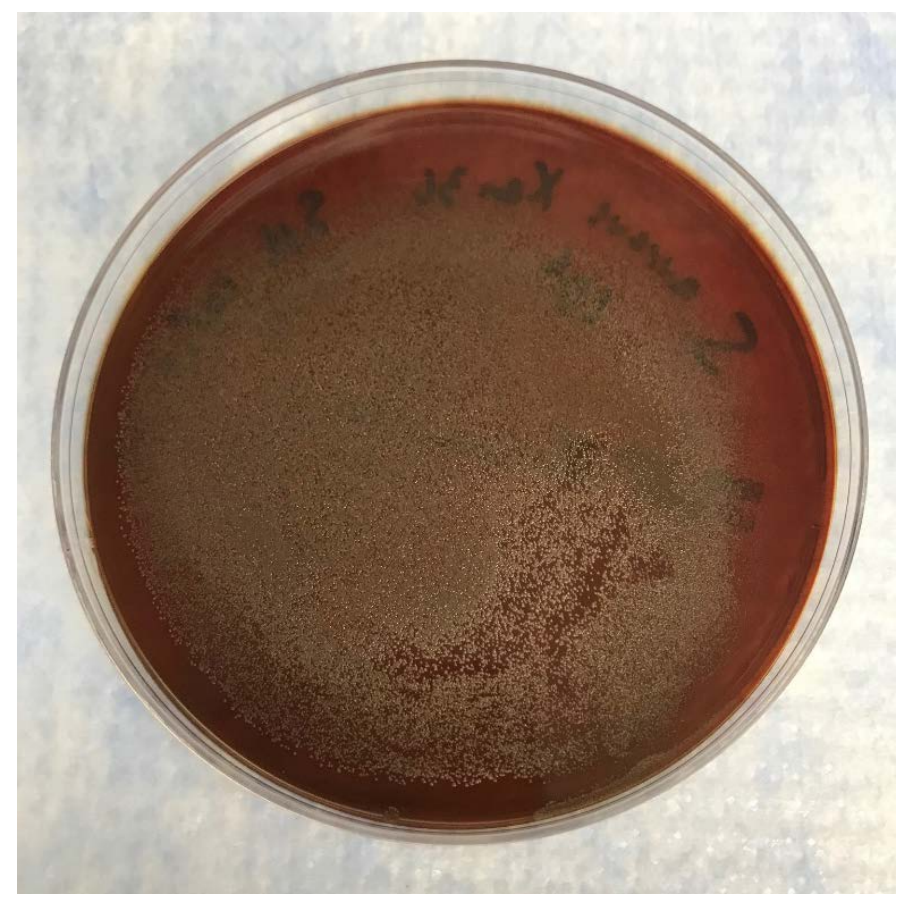

Figure 12: Sample BAP with even distribution of bacterial growth. 


\section{Teeth}

Fifty extracted human maxillary anterior teeth, stored in (1 part 8.25\% NaOCl, 1 part glycerin, 3 parts distilled water) to prevent bacterial growth were obtained from the West Virginia University School of Dentistry Research Labs Tooth Depository (IRB \#: T2017.07). Teeth were decoronated and the root length was standardized to approximately $16 \mathrm{~mm}$ (Figure 13). After decoronation, the teeth were immersed in $8.25 \% \mathrm{NaOCl}$ for 5 hours and then stored in distilled water. Cleaning, shaping and obturation of the root segments was performed under an operating microscope (Global Surgical Corporation, St. Louis, MO) (Figure 14). Canal patency was confirmed with a \#10 K-file and working length was determined by subtracting $0.5 \mathrm{~mm}$ from the length at which this file was visible at the foramen. Each canal was instrumented with ProTaper Universal rotary instruments (Dentsply, Tulsa, OK) according to the manufacturer’s recommendations to a size F4 (40/06 at D0) (Figure 15). After each file use, each canal was irrigated with $1 \mathrm{~mL}$ of $8.25 \% \mathrm{NaOCl}$. A final rinse was performed with $3 \mathrm{~mL}$ of $17 \%$ EDTA (Vista Dental Products, Racine, WI) (Figure 16) and the canals were dried with paper points (Dentsply, Tulsa, OK). After standardization of the instrumentation, the teeth were randomly divided into three experimental groups $(n=12)$ and two control groups (5 positive and 5 negative). The final four teeth were used in the IVIS pilot study. 


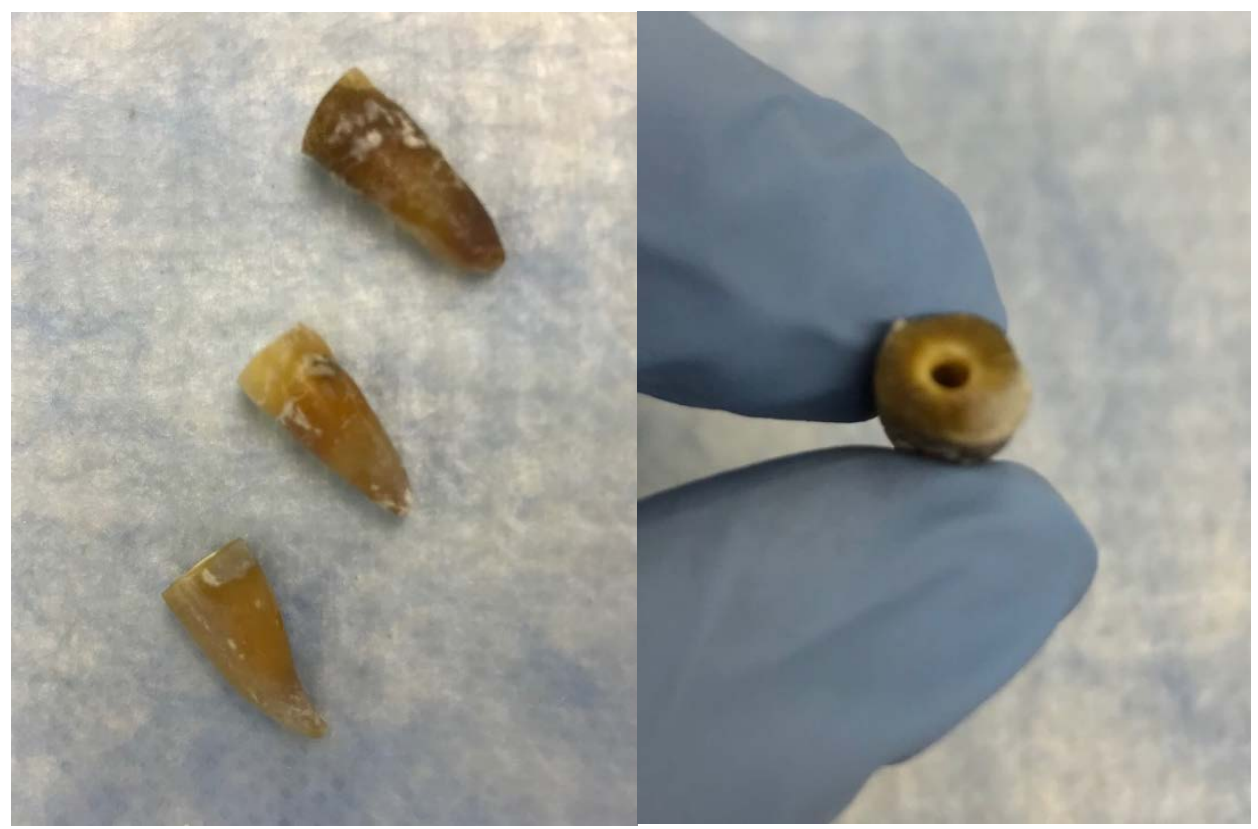

Figure 13: Sample of decoronated maxillary anterior teeth (side and incisal views).

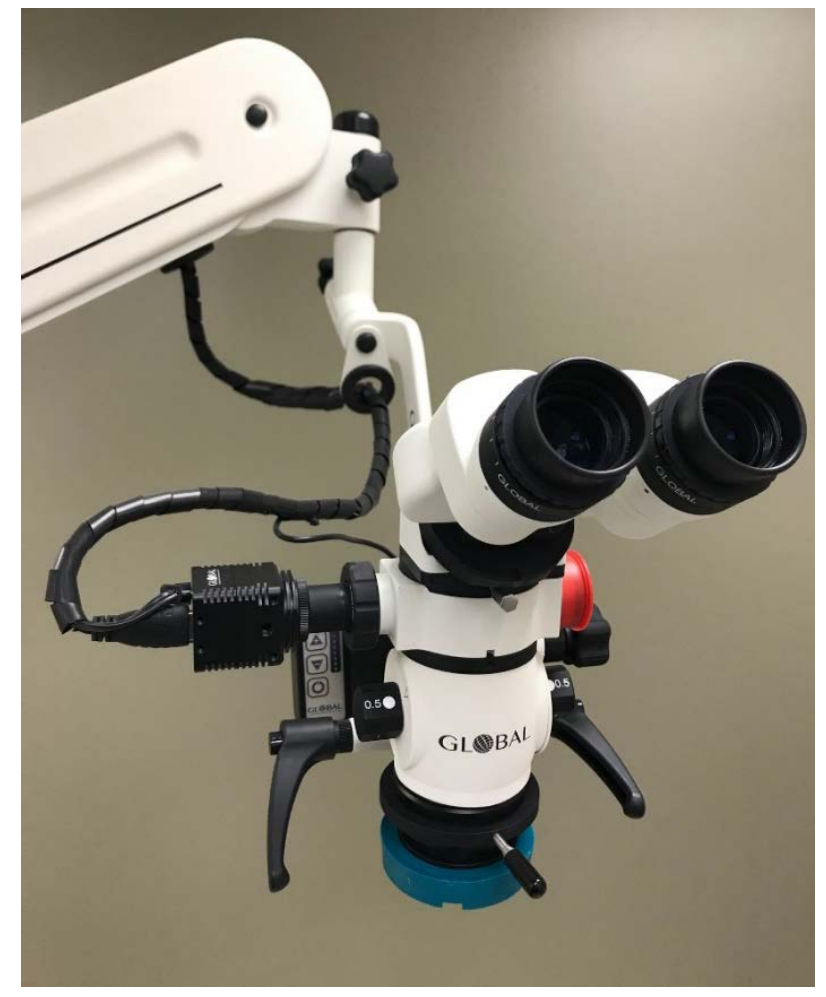

Figure 14: Dental operating microscope used for instrumentation and obturation of samples (Global Surgical Corporation, St. Louis, MO). 


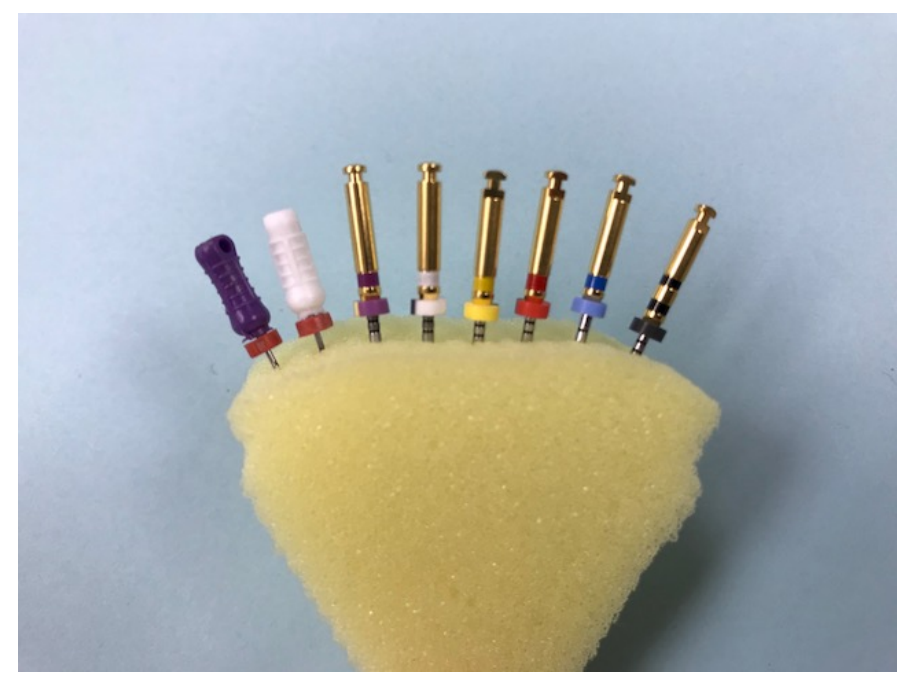

Figure 15: Sequence of hand files and ProTaper Universal rotary files used to instrument canals.

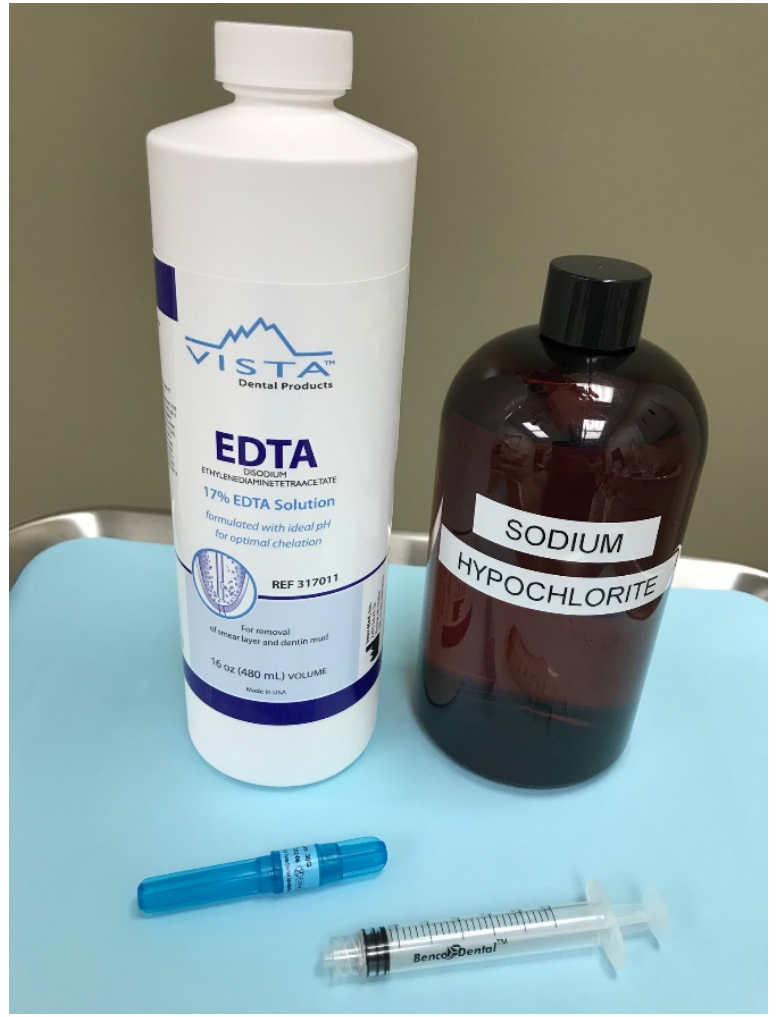

Figure 16: Irrigating solutions and sample irrigation syringe and tip used during cleaning and shaping procedures. 
Obturation of the three experimental groups was performed with a single-cone technique using a ProTaper F4 master cone (Dentsply, Tulsa, OK) (Figure 17). The master cone size was chosen to match the instrumented canal size. The three sealers tested included EndoSequence BC sealer (Brasseler USA, Savannah, GA), ThermaSeal Plus Ribbon Sealer (Dentsply Tulsa Dental Specialties, Tulsa, OK), and GuttaFlow 2 (Coltene/Whaledent Inc., Cuyahoga Falls, OH). This single-cone method of obturation was deemed acceptable by each of the manufacturers.

The sealer for each group was placed on a sterile glass slab and the master cone was coated in the sealer. The coated cone was gently placed in each canal to obtain a thin coating of the walls. The cone was withdrawn and more sealer was placed on the apical third of the master cone. The cone was then carefully seated to full working length. The master cone was seared off with an Elements Free downpack unit (Kerr Corporation, Orange, CA) (Figure 18) and lightly condensed with an endodontic plugger to a level that allowed $14 \mathrm{~mm}$ of gutta percha to remain. This provided an unfilled coronal trough where the bacteria could be introduced.

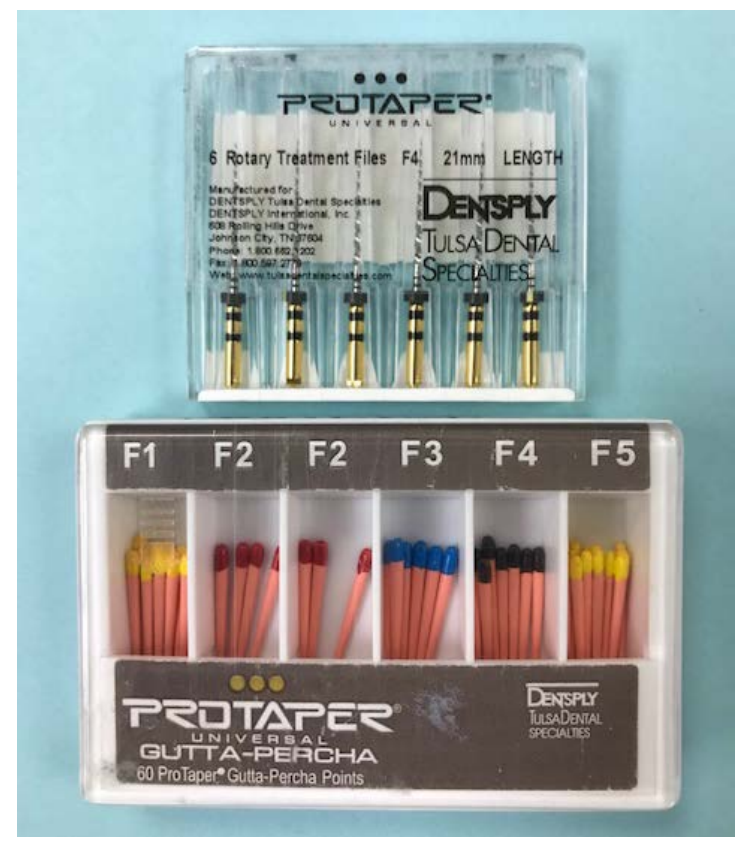

Figure 17: Final ProTaper Universal file used during instrumentation (F4) and corresponding ProTaper Universal gutta percha points. 


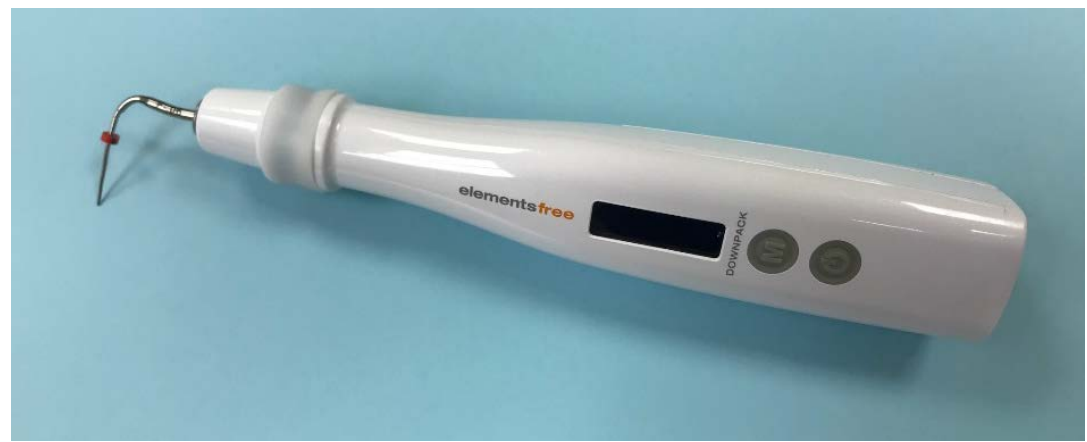

Figure 18: Elements Free downpack unit (Kerr Corporation, Orange, CA) used to sear off gutta percha.

Positive controls were not obturated. On all teeth in the positive control and experimental groups, three layers of clear nail polish were applied, except for the occlusal table and the apical $2 \mathrm{~mm}$ of root. This was adopted from the methods laid out by Fransen. ${ }^{40}$ The negative controls were obturated with ThermaSeal Plus Ribbon sealer using the same single-cone technique. However, for this group, three coats of clear nail polish covered $100 \%$ of the root surface. The teeth were stored for 2 days at $37^{\circ} \mathrm{C}$ and $100 \%$ relative humidity to allow the sealers to completely set before evaluation of bacterial leakage.

\section{Evaluation of Leakage}

Evaluation of bacterial leakage was done in two ways. Both methods involved preparation of an experimental apparatus that was adapted from a study by Fransen. ${ }^{40}$ The experimental apparatus was constructed as follows: the ends of 1.7-mL Posi-Click plastic tubes (Denville Scientific Inc., Holliston, MA) were removed so that the teeth could be inserted with their apices pointing out the end. Water resistant putty (J-B Weld Company, Sulphur Springs, TX) and super glue (Loctite, Rocky Hill, CT) were used to seal the junction between the plastic 
tube and root, and two coats of clear nail polish were placed over the set putty/glue. The cap of a 20-mL liquid scintillation vial (Scientific Specialties Service, Hanover, MD) was modified so that the plastic tube and tooth assembly could be snugly placed through it. The tube was then sealed to the cap with super glue and nail polish. The total apparatus was sterilized by a 12-hour cycle in ethylene oxide gas.

To determine the viability of using the In Vivo Imaging System (IVIS) as a method of evaluating bacterial leakage, a short pilot study was accomplished. This involved evaluation of four teeth in the same experimental apparatus. After cleaning and shaping as mentioned earlier, one tooth was left unobturated and three teeth were obturated with ThermaSeal Plus Ribbon sealer. The gutta percha in these three teeth was burned off at a level that allowed either $5 \mathrm{~mm}$, $10 \mathrm{~mm}$, or $15 \mathrm{~mm}$ to remain. An additional instrumented tooth was placed in a Posi-Click tube as a control. By omitting the glass vial in this tooth, it could be tested if the glass in the experimental apparatuses would cause any imaging interference.

$0.1 \mathrm{ml}$ of a 1 x $10^{9} \mathrm{cfu} / \mathrm{mL}$ culture of Staphylococcus aureus Xen36 was placed in another Posi-Click tube by itself as an additional control. The root canals in the four samples and additional control tooth were inoculated with $0.1 \mathrm{~mL}$ of the $S$. aureus Xen36 and a scan was taken with the IVIS. The IVIS was linked to a data-acquisition computer running LivingImage $^{\mathrm{TM}}$ software, which produced real-time images of each scan (Figure 19). Scans were taken to show whether apical migration of bacteria could be detected at varying levels in the root. The scans were taken at Days $0,3,7$, and 10 . 


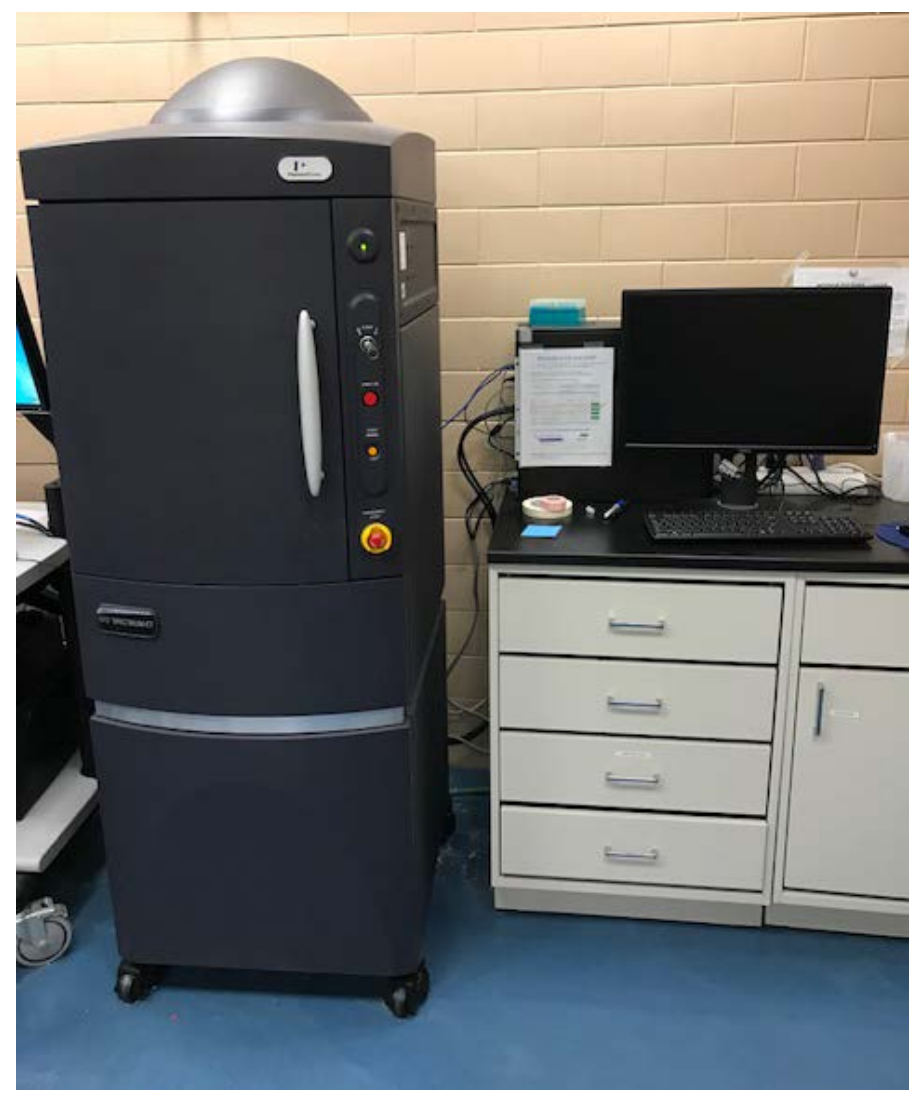

Figure 19: In Vivo Imaging System (IVIS) linked to data-acquisition computer.

The remaining forty-six apparatuses were evaluated in the same method as Fransen’s study. The scintillation vials were filled with Difco Purple Broth Base (Beckton Dickinson, Sparks, MD) (Figure 20) to a level that allowed approximately $2 \mathrm{~mm}$ of the root end to be submerged. This solution contained a carbohydrate (1\% D-Fructose) that the bacteria can ferment to produce acid. When the $\mathrm{pH}$ of the broth drops below 6.8 it changes color from purple to yellow (Figure 21). The apparatuses were incubated at $37^{\circ} \mathrm{C}$ for 3 days and the broth was inspected for a color change to ensure that no contamination occurred before inoculation with bacteria. $0.1 \mathrm{~mL}$ of the $1 \times 10^{6} \mathrm{cfu} / \mathrm{mL}$ culture of Staphylococcus aureus Xen36 was used to inoculate the top chamber of the tube/tooth apparatus. The apparatuses were incubated at $37^{\circ} \mathrm{C}$ for up to 50 days (Figure 22). Apparatuses were re-inoculated with a freshly prepared $1 \times 10^{6}$ 
cfu/mL solution of Staphylococcus aureus Xen36 every 7 days. The teeth were checked daily to monitor changes in broth color. Teeth were declared to have fully leaked at the first sign of color change from purple to yellow.

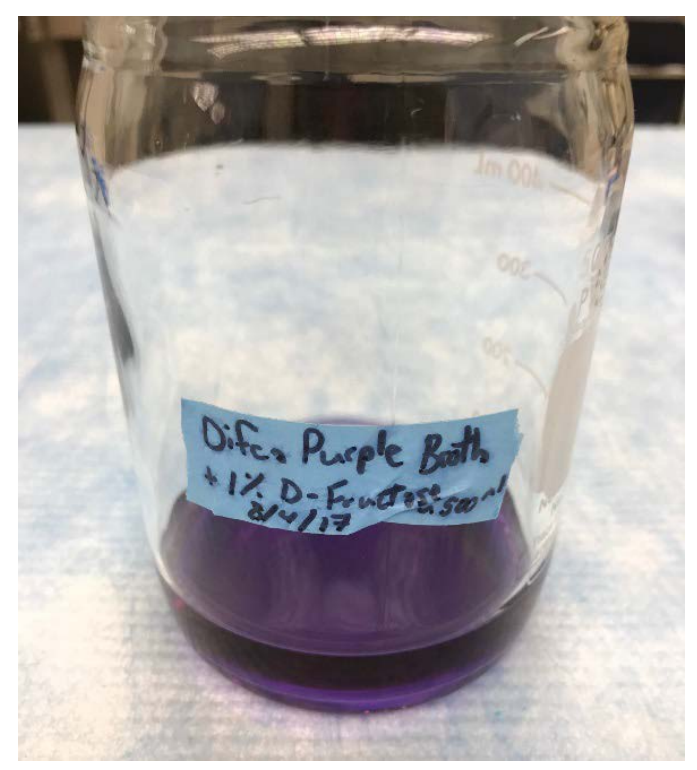

Figure 20: Difco Purple Broth Base with 1\% D-Fructose carbohydrate used in the sample vials for inspection of fermentation reaction.

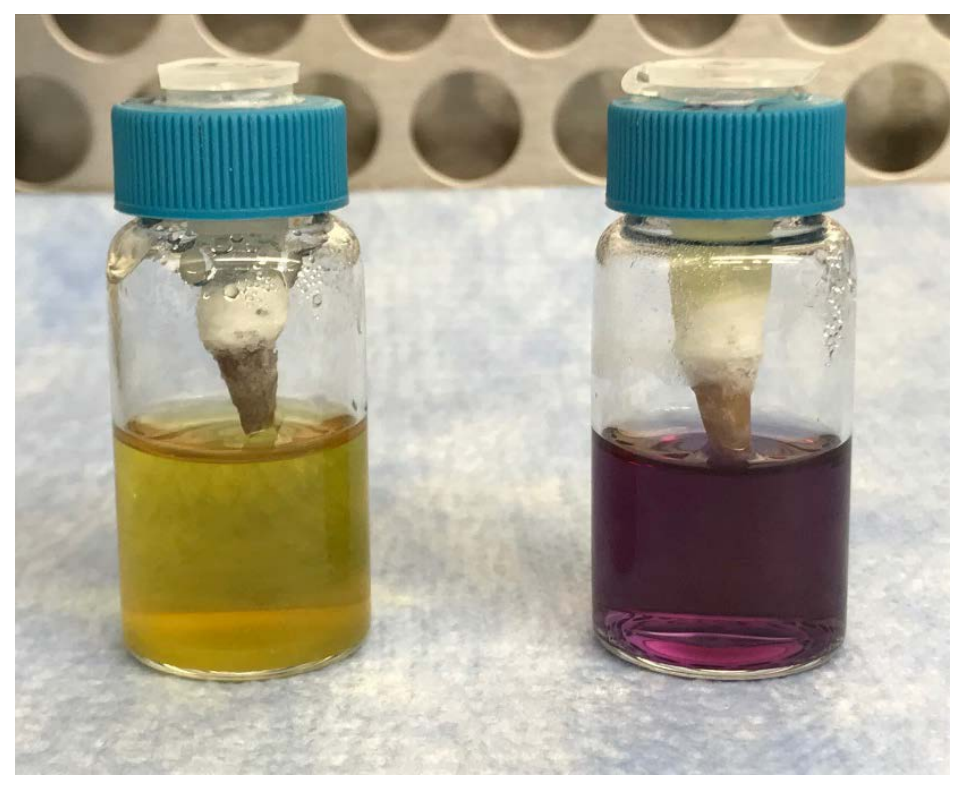

Figure 21: Sample apparatuses - a positive control on the left showing bacterial leakage through entire RCS (yellow color change) and a negative control on the right without leakage (broth still purple in color). 


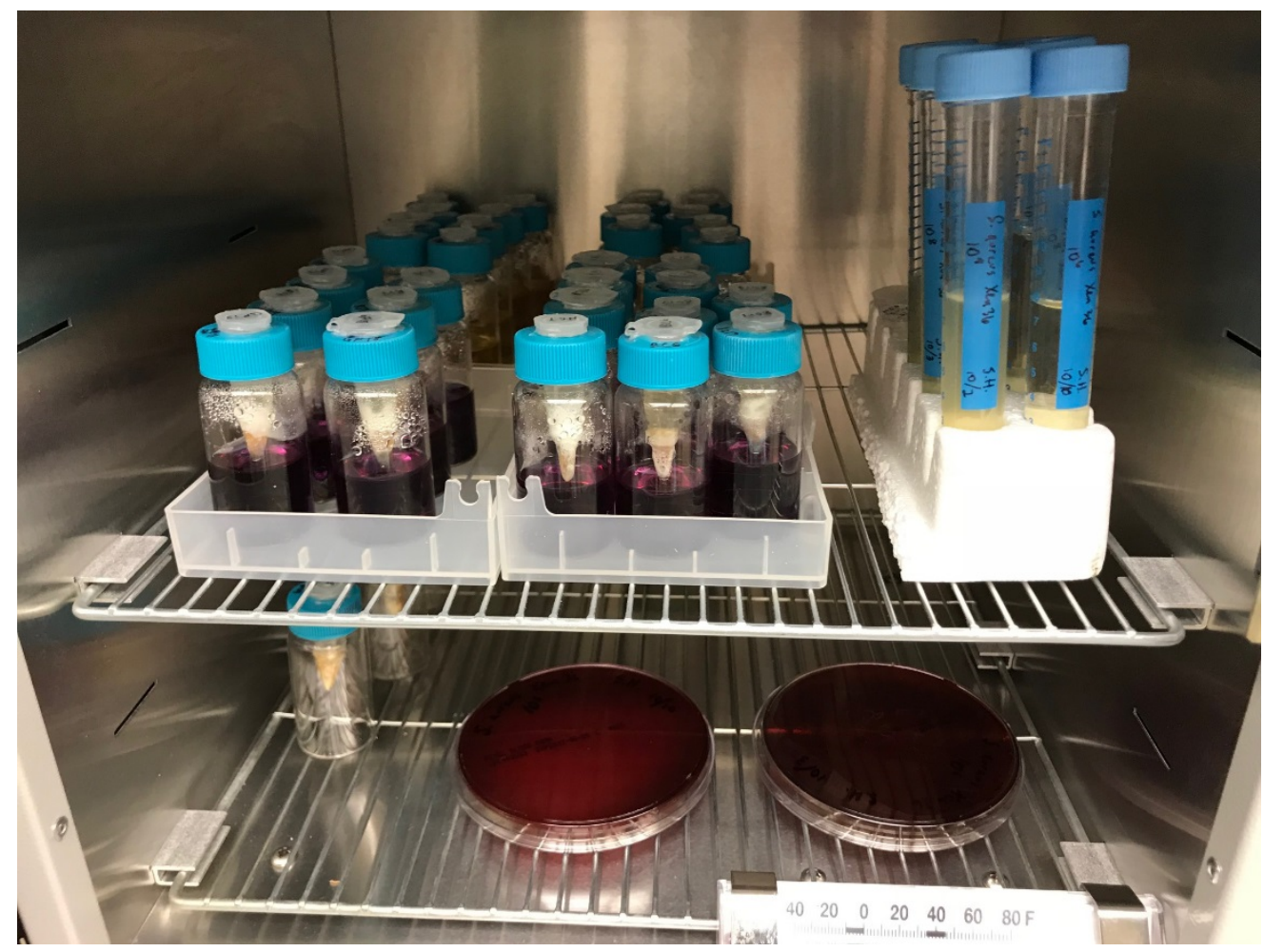

Figure 22: Storage of samples, stock solutions, and BAPs in incubator at $37^{\circ} \mathrm{C}$.

\section{$\underline{\text { Statistical Analysis }}$}

To evaluate survival, teeth were assigned a status number. If full bacterial leakage occurred (broth color change from purple to yellow) in a sample tooth, it was given the status number " 1 ”. If a tooth did not leak by the end of the 50 -day observation period, it was assigned the status number "0". Survival curves were prepared for each experimental group using the Kaplan-Meier method. The curves were compared using the log-rank test at a significance level of 0.05 . 


\section{Chapter 4}

\section{$\underline{\text { Results }}$}

The pilot study was unable to provide accurate information on the localization and quantification of bacteria in the four sample teeth. Bacteria leaked all the way through the sample tooth that was left unobturated, and the solution laid in the bottom of the scintillation vial. IVIS imaging showed where this bacteria had pooled in the vial, but bacteria was unable to be seen in the tooth. In the remaining sample teeth, minimal to no bacterial presence was shown. A small quantity of bacteria could be seen on the tops of some teeth where the bacterial solution had pooled, but no bacteria could be seen through the tooth in the outline of the canal space (Figure 23). The Posi-Click tube with $1 \times 10^{9} \mathrm{cfu} / \mathrm{mL}$ S. aureus Xen36 provided some light transmission (Figure 24).
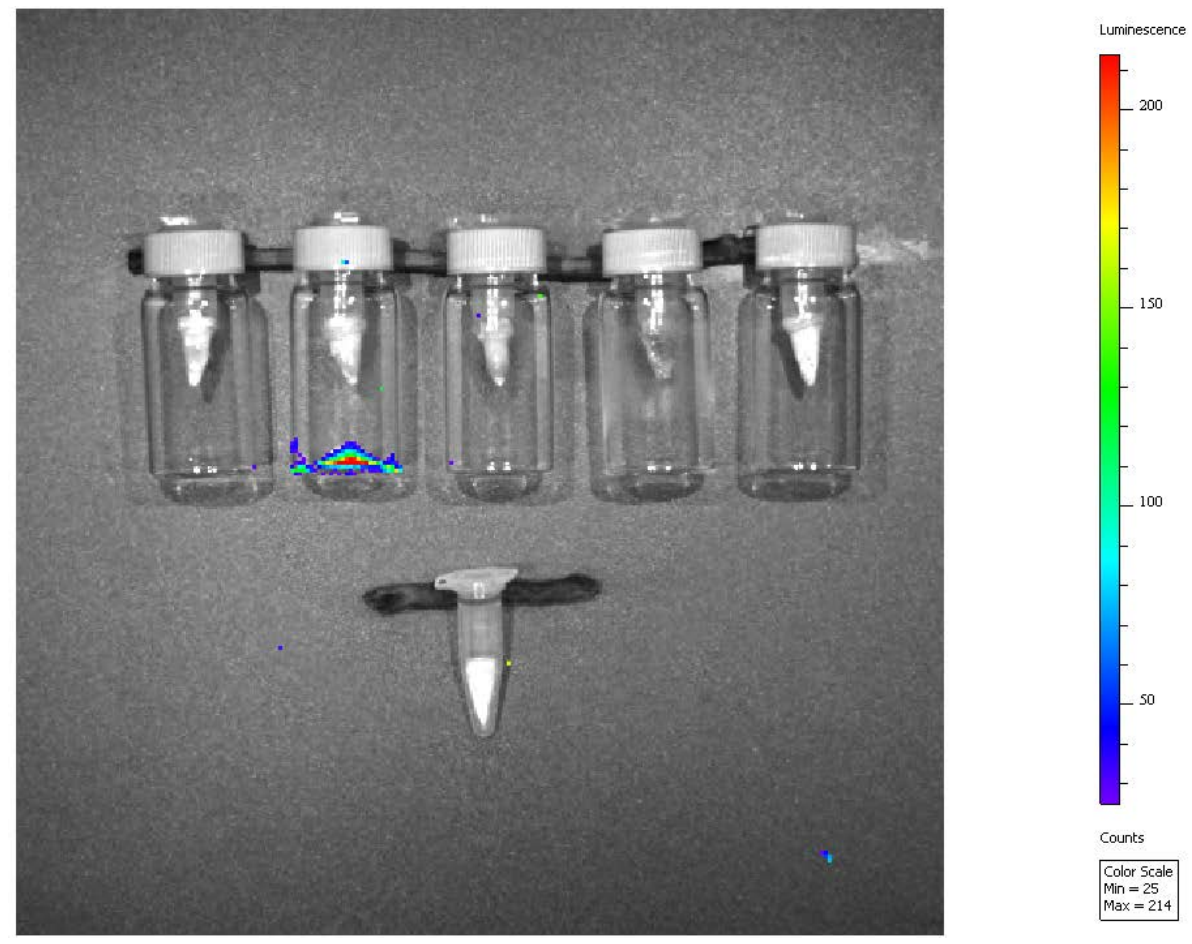

Figure 23: Bioluminescence produced by S. aureus Xen36 at 7 days. Vials in top row from left to right are: negative control (no bacteria), un-obturated tooth, tooth with $5 \mathrm{~mm}$ GP remaining, tooth with $10 \mathrm{~mm}$ GP remaining, tooth with $15 \mathrm{~mm}$ GP remaining. Bottom tube contains an unobturated tooth that was inoculated with the same bacteria. 

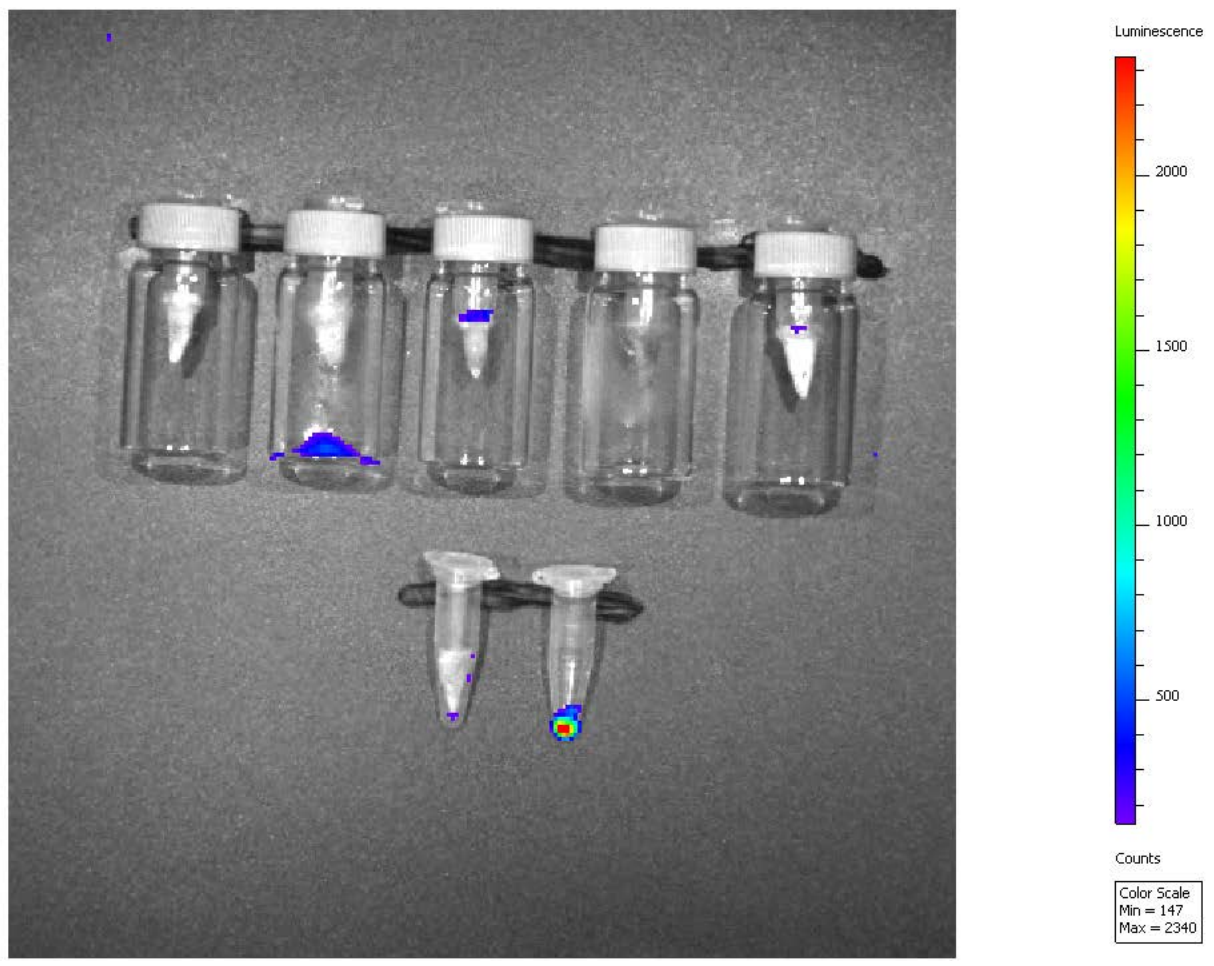

Figure 24: Bioluminescence produced by S. aureus Xen36 at 10 days. Vials in top row from left to right are: negative control (no bacteria), un-obturated tooth, tooth with $5 \mathrm{~mm}$ GP remaining, tooth with $10 \mathrm{~mm}$ GP remaining, tooth with $15 \mathrm{~mm}$ GP remaining. In the bottom row, an unobturated, inoculated tooth is on the left and a tube containing $0.1 \mathrm{ml}$ of $1 \times 10^{9} \mathrm{cfu} / \mathrm{mL} S$. aureus Xen36 is on the right.

For the traditional bacterial leakage study, all positive control teeth leaked within the first 24 hours. None of the negative control teeth leaked during the entire 50-day observation period. Data collected for the experimental groups can be seen in the Appendix. The Kaplan Meier survival curves are shown in Figure 25. After the first 24 hours, three teeth leaked in both the EndoSequence BC Sealer and GuttaFlow 2 groups compared to four teeth in the ThermaSeal Plus Ribbon Sealer group. After one week, all three groups had a survival rate of 58.3\%. After 50 days, all but one of the teeth in the ThermaSeal Plus Ribbon Sealer group had leaked, and three teeth survived from each of the EndoSequence BC Sealer and GuttaFlow 2 groups. Table 1 shows the survival rates for each experimental group at different time intervals. The log-rank 
test showed no statistically significant differences between the three groups with respect to leakage over time $(\mathrm{p}=0.665)$.

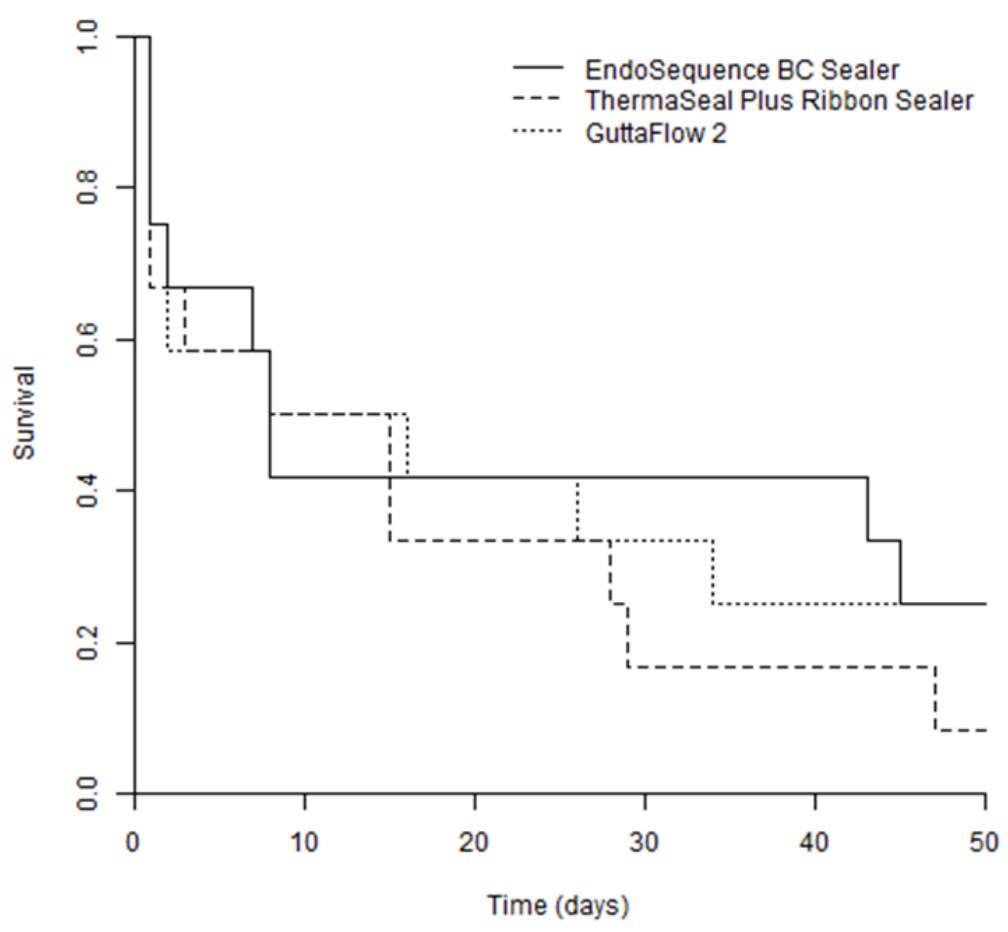

Figure 25: Survival rates (teeth without complete bacterial leakage) over the 50-day observation period for each of the three experimental groups.

\begin{tabular}{|c|c|c|c|}
\hline Day & \multicolumn{3}{|c|}{ Percent Survival } \\
\hline $\begin{array}{c}\text { EndoSequence BC } \\
\text { Sealer }\end{array}$ & $\begin{array}{c}\text { ThermaSeal Plus } \\
\text { Ribbon Sealer }\end{array}$ & GuttaFlow 2 \\
\hline 1 & $75.0 \%$ & $66.7 \%$ & $75.0 \%$ \\
\hline 7 & $58.3 \%$ & $58.3 \%$ & $58.3 \%$ \\
\hline 21 & $41.7 \%$ & $33.3 \%$ & $41.7 \%$ \\
\hline 30 & $41.7 \%$ & $16.7 \%$ & $33.3 \%$ \\
\hline 50 & $25.0 \%$ & $8.3 \%$ & $25.0 \%$ \\
\hline
\end{tabular}

Table 1: Survival rates of the three experimental groups at different observation times. 


\section{$\underline{\text { Discussion }}$}

The purpose of this project was twofold: to evaluate the resistance of three newly developed root canal sealers to bacterial leakage in teeth with lost coronal seals and to determine if bioluminescent bacteria could be utilized in coronal leakage studies to give more spatial and quantitative information. Based on the findings in Sedgley's study, it was predicted that similar detection of bioluminescent bacteria would be found in a bacterial leakage apparatus. This study, however, was unable to produce similar detection of bacteria in the RCS. Images produced by the IVIS appeared to only show bacteria in some areas where a larger volume had pooled and didn’t show any bacteria in the roots of the sample teeth (Figures 23, 24). One difference in this study compared to that of Sedgley’s was the apical preparation size. In Sedgley’s study, each experimental tooth was instrumented to a minimum apical size of 60, while this study completed instrumentation at a 40 (size F4 ProTaper Universal file). ${ }^{44}$ This larger apical preparation size may have allowed a larger volume of bacteria to gather in the canals of Sedgley’s experimental teeth. The experimental apparatus may have been another factor that limited light transmission. Due to biosafety requirements, the experimental teeth in this study had to be contained in sealed apparatuses while being imaged in the IVIS, while in Sedgley’s study, it appears that the teeth were placed directly in the machine’s chamber. Although images in this study were able to show light transmission through the glass scintillation vials and plastic Posi-Click tubes, the combination of these materials along with the root thickness and nail polish covering the roots may have limited transmission. Further studies looking at different apical preparation sizes and different experimental apparatus designs would be needed before suggesting that bioluminescent imaging is an appropriate method of analyzing bacterial leakage in obturated roots. 
The results from the traditional bacterial leakage model showed that loss of a good coronal seal could cause re-infection of the entire RCS. The unobturated positive controls all leaked within 24 hours, showing that bacteria did travel through the RCS quickly when no barrier was in place to prevent its movement. Since none of the negative controls leaked during the 50-day observation period, it appears that the experimental apparatuses were properly constructed and only allowed bacterial leakage through the RCS. Although survival rates of the experimental groups were different at certain time points, the log-rank test found no statistically significant differences between the groups with respect to leakage over time. The lack of statistical significance between the three experimental groups warrants acceptance of the null hypothesis.

Although no difference was found between the three sealers over time, some general trends can be shown regarding the single-cone obturation technique. The fact that all three groups had a survival rate of only 58.3\% after the first week shows that the single-cone method of obturation does not provide resistance to leakage in many teeth. This finding stresses the importance of timely placement of a high quality coronal restoration after completion of root canal therapy. If a temporary restoration is placed, waiting longer than the recommended 3-4 weeks to have a definitive restoration could jeopardize the long-term success of the root canal therapy.

After the first week, leakage in the experimental groups leveled off to some degree. For example, the experimental teeth in the EndoSequence BC sealer group had no leakage from Day 9 through Day 42. It is likely that the teeth in the EndoSequence BC sealer group that did not leak early on were able to create a hydroxyapatite layer between the sealer and dentin, and this layer was able to help resist leakage for a period of time. These findings show that sealers can 
possibly resist bacterial leakage for some time if factors like sealer thickness and canal anatomy are ideal. However, it is impossible to know from clinical and radiographic analysis that such microscopic conditions exist.

Skinner and Himel showed that sealers play a critical role in the seal of the RCS. ${ }^{51}$ Compared to cold lateral condensation and warm vertical condensation where gutta percha fills in most irregularities in the RCS, single-cone techniques rely more on the sealer to fill these spaces. Although greater taper gutta percha cones have been designed to perfectly match the nickel-titanium rotary files used today, ${ }^{18}$ the presence of fins and other canal irregularities may cause a thicker sealer interface with single-cone obturation techniques. ${ }^{52}$ De-Deus found that a greater sealer thickness negatively influenced the sealing ability of most sealers. ${ }^{53}$ The range of bacterial leakage found in this study could be partially attributed to different sealer thickness in the experimental teeth.

It is advantageous for a root canal sealer to be able to adhere to the intraradicular dentin through frictional resistance or micromechanical retention so that the sealer-dentin interface is retained during tooth flexure or operative procedures. ${ }^{54} \mathrm{AH}$ Plus sealer (equivalent to ThermaSeal Plus) and iRoot SP (EndoSequence BC sealer) have been shown to produce high bond strengths with dentin. ${ }^{23,55}$ Open epoxide rings in AH Plus can form a covalent bond with exposed amino groups in the dentin collagen network. ${ }^{56}$ The calcium silicate composition of EndoSequence BC sealer releases calcium and hydroxyl ions which can create an apatite layer when they come in contact with phosphate-containing dentinal fluids. This layer enables a chemical bond of the sealer to dentin. ${ }^{54,57}$ GuttaFlow 2 relies on its slight expansion on setting and its low solubility for its seal, because it does not chemically bond with dentin. ${ }^{58}$ The resistance of some experimental teeth to bacterial leakage are likely due to these properties. 
The low survival rates at the end of the 50-day observation period show that if an endodontically treated tooth loses its coronal seal for any extended period of time, re-treatment of the root canal would be necessary. Since some experimental teeth did not leak by the conclusion of the observation period, it appears that these sealers do have some capability of long-term sealing. A longer observation time may be able to show the full potential of these sealers concerning bacterial leakage resistance. However, the high rate of early leakage shown in this study seems to make such information clinically insignificant.

The lack of statistical significance in this study may be partially due to both sample size as well as experimental design. Fransen was also unable to find statistically significant differences between three different obturation techniques, ActiV GP/Glass Ionomer Sealer, Resilon/Epiphany, and Gutta-Percha/AH Plus, despite having a larger sample size than the current study ( $n=20$ per group). ${ }^{40}$ On the other hand, Monticelli was able to show significant differences between groups using the same sample size as the current study ( $n=12$ per group). In their study, warm vertical compaction with AH Plus had significantly less leakage over time when compared to two single-cone techniques, ActiV GP and GuttaFlow. ${ }^{39}$ A larger sample size in our study would provide greater discriminative power.

A bacterial leakage model utilizing a singular bacterial species, Staphylococcus aureus Xen36, was used in this study. This bacterium was chosen because it is a facultative anaerobe that has the ability to survive by fermentation and has bioluminescent capabilities that allow it to be visible when evaluated with an IVIS. Other authors have utilized a similar bacterial leakage model with singular bacterial species. ${ }^{38-40}$ Fresh human saliva has been used in other bacterial leakage studies ${ }^{5,41,42}$ in an attempt to have a model that provides the proteins, enzymes, and 
bacterial populations found in normal clinical conditions. However, a solution with a single bacterial species is easier to standardize for experimental use so that all groups can be compared. Although bacterial leakage models are more clinically relevant than fluid filtration and dye leakage studies, they do not provide spatial information of where the bacteria are localized in the canal. The pilot study using the IVIS was conducted in an attempt to address this problem. Gutta percha was removed to varying levels in the pilot teeth to see if this type of imaging could visualize the bacteria at that level. Obtaining such information could be beneficial in providing guidelines for clinical situations. For example, if the study was able to show that after one week, teeth obturated with a certain material or technique leaked an average of $3 \mathrm{~mm}$, the need for retreatment may be avoided. In such a case, just the coronal gutta percha would need removed for disinfection rather than all of the obturation material. Unfortunately, additional experiments would be necessary to see if this type of information could be gathered by the IVIS. Further experiments could be conducted with larger apical preparations in the teeth, different experimental apparatus designs, and/or the use of different species of bioluminescent bacteria.

The amount of bacterial leakage needed to cause clinical root canal therapy failure is unknown, ${ }^{59}$ so it is difficult to determine how much the results of the present study translate into clinical outcomes. The high prevalence of early contamination and minimal survival at the end of the 50-day observation period show that teeth obturated with the single-cone technique would need retreated if they presented with a lost coronal seal. Single-cone obturation techniques with newer categories of sealers should be analyzed further with animal studies and/or randomized clinical trials. 


\section{Chapter 5}

\section{Conclusion}

Employing a bacterial leakage model, the results of the present study show that in the absence of a coronal seal, the single-cone method of root canal obturation does not provide longterm sealing ability in many teeth. Although many contemporary sealers claim to be able to create an adhesive bond with the dentin and/or gutta percha to better seal the RCS, this appears to be inadequate to stop bacterial leakage in some teeth. The presence of fins and other microscopic canal irregularities may increase the sealer thickness and prevalence of voids, which can create portals for bacterial infiltration. Although survival was different for each of the experimental groups at certain time points, there were no statistically significant differences between EndoSequence BC Sealer, ThermaSeal Plus Ribbon Sealer, and GuttaFlow 2 with respect to leakage over time.

A pilot study using a bioluminescent strain of S. aureus (Xen 36) and an IVIS was also conducted in an attempt to better localize and quantify the bacterial leakage through the RCS. Unfortunately, experimentation with this method of imaging was unable to produce adequate visualization of the bacteria. Further studies should be piloted to see if this type of imaging could be beneficial for analyzing obturated teeth. 


\section{Works Cited}

1. Swanson K, Madison S. An evaluation of coronal microleakage in endodontically treated teeth. Part I. Time periods. J Endod 1987;13:56.

2. Madison S, Swanson K, Chiles SA. An evaluation of coronal microleakage in endodontically treated teeth. Part II. Sealer type. J Endod 1987;13:109.

3. Madison S, Wilcox L. An evaluation of coronal microleakage in endodontically treated teeth. Part III. In vivo study. J Endod 1988;14:455.

4. Coronal Leakage: Clinical and Biological Implications in Endodontic Success. Endodontics: Colleagues for Excellence. Fall/Winter 2002.

5. Khayat A, Lee SJ, Torabinejad. Human saliva penetration of coronally unsealed obturated root canals. J Endod 1993;19:458-61.

6. Michailesco PM, Valcarcel J, Grieve AR, Levallois B, Lerner D. Bacterial leakage in endodontics: an improved method for quantification. J Endod 1996;22:535-9.

7. Schilder H. Filling root canals in three dimensions. Dent Clin North Am 1967;11:72344.

8. ElAyouti A, Achleithner C, Löst C, Weiger R. Homogeneity and adaptation of a new gutta-percha paste to root canal walls. J Endod 2005;9:687-90.

9. Kakehashi S, Stanley H, Fitzgerald R. The effect of surgical exposures of dental pulps in germ-free and conventional laboratory rats. Oral Surg Oral Med Oral Pathol 1965;20:340 $-9$.

10. Sundqvist G. Associations between microbial species in dental root canal infections. Oral Microbiol Immunol. 1992 Oct; 7(5):257-62. 
11. Shuping G, Ørstavik D, Sigurdsson A, Trope M. Reduction of intracanal bacteria using nickel-titanium rotary instrumentation and various medications. J Endod 2000;26:751-5.

12. Usman N, Baumgartner JC, Marshall JG. Influence of instrument size on root canal debridement. J Endod. 2004;30(2):110-112.

13. Al-Dewani N, Hayes SJ, Dummer PM. Comparison of laterally condensed and low temperature thermoplasticized gutta-percha root fillings. J Endod 2000;26:733-8.

14. Wu, M.-K. and Wesselink, P.R. Endodontic leakage studies reconsidered. Part 1. Methodology, application and relevance. Int Endod J. 1993;26:37-43.

15. Canal Preparation and Obturation: An Updated View of the Two Pillars of Nonsurgical Endodontics. Endodontics: Colleagues for Excellence. Fall 2016.

16. Whitworth J. Methods of filling root canals: principles and practices. Endodontic Topics. 2005;12:2-24.

17. Beatty RG. The effect of standard or serial preparation on single cone obturation. Int Endod J 1987;20:276-81.

18. Gordon MPJ, Love RM, Chandler NP. An evaluation of .06 tapered gutta-percha cones for filling of .06 taper prepared curved root canals. Int Endod J 2005;38:87-96.

19. Gillespie WT, Loushine RJ, Weller RN, et al. Improving the performance of EndoREZ root canal sealer with a dual-cured two-step self-etch adhesive. II. Apical and coronal seal. J Endod 2006;32:771-5.

20. Sagsen B, Er O, Kahraman Y, Orucoglu H. Evaluation of microleakage of roots filled with different techniques with a computerized fluid filtration technique. J Endod 2006;32,1168-70. 
21. Waltimo TM, Boiesen J, Eriksen HM, Ørstavik D. Clinical performance of three endodontic sealers. Oral Surg Oral Med Oral Pathol Oral Radiol Endod 2001;92:89-92.

22. Li GH, Niu LN, Zhang W, Olsen M, De-Deus G, Eid AA, et al. Ability of new obturation materials to improve the seal of the root canal system: a review. Acta Biomater 2014;10:1050-63.

23. Nagas E, Uyanik MO, Eymirli A, Cehreli ZC, Vallittu PK, Lassila LVJ, Durmaz V. Dentin moisture conditions affect the adhesion of root canal sealers. J Endod 2012;38(2): 240-4.

24. EndoSequence BC Sealer. Instructions for Use. Brasseler USA, Savannah, Georgia. 2008.

25. Zhang H, Shen Y, Ruse ND, Haapasalo M. Antibacterial activity of endodontic sealers by modified direct contact test against Enterococcus faecalis. J Endod 2009;35:1051-5.

26. Zhang W, Li Z, Peng B. Assessment of a new root canal sealer's apical sealing ability. Oral Surg Oral Med Oral Pathol Oral Radiol Endod 2009;107:e79-82.

27. Zhang W, Li Z, Peng B. Ex vivo cytotoxicity of a new calcium silicate-based canal filling material. Int Endod J 2010;43:769-774.

28. ThermaSeal Plus Ribbon Root Canal Sealer. Directions for Use. DENTSPLY Tulsa Dental Specialties, Johnson City, Tennessee.

29. Pinna L, Brackett MG, Lockwood PE, Huffman BP, Mai S, Cotti E, Dettori C, Pashley DH, Tay FR. In vitro cytotoxicity evaluation of a self-adhesive, methacrylate resin-based root canal sealer. J Endod 2008;34(9):1085-8.

30. T.H. Huang, S.J. Ding, T.Z. Hsu, Z.D. Lee, C.T. Kao. Root canal sealers induce cytotoxicity and necrosis. J Mater Sci Mater Med 2004;15:767-771. 
31. Haikel Y, Freymann M, Fanti V, Claisse A, Poumier F, Watson M. Apical microleakage of radiolabeled lysozyme over time in three techniques of root canal obturation. J Endod 2000;26(3):148-52.

32. Hygenic GuttaFlow2. Instructions for Use. Coltene/Whaledent Inc., Cuyahoga Falls, OH. 2013.

33. Mandal P, Zhao J, Sah SK, Huang Y, Liu J. In vitro cytotoxicity of Guttaflow 2 on human gingival fibroblasts. J Endod. 2014;40(8):1156-9.

34. Ray HA, Trope M. Periapical status of endodontically treated teeth in relation to the technical quality of the root filling and the coronal restoration. Int Endodont J 1995; 28:12-18.

35. Saunders WP, Saunders EM. Coronal leakage as a cause of failure in root-canal therapy: a review. Endod Dent Traumatol 1994; 10:105-108.

36. Monticelli F, Sword J, Martin RL, et al. Sealing properties of two contemporary singlecone obturation systems. Int Endod J 2007;40:374-85.

37. Pommel L, Camps J. Effects of pressure and measurement time on the fluid filtration method in endodontics. J Endod 2001;27:256-9.

38. Torabinejad M, LJng B, Kettering JD. In vitro bacterial penetration of coronally unsealed endodonticaliy treated teeth. J Endod 1990;16:566.

39. Monticelli F, Sadek FT, Schuster GS, et al. Efficacy of two contemporary single-cone filling techniques in preventing bacterial leakage. J Endod 2007;33:310-3.

40. Fransen JN, He J, Glickman GN, et al. Comparative Assessment of ActiV GP/Glass Ionomer Sealer, Resilon/Epiphany, and Gutta-Percha/AH Plus Obturation: A Bacterial Leakage Study. J Endod 2008;34:725-7. 
41. Magura ME, Kafrawy AH, Brown CE Jr, Newton CW. Human Saliva Coronal Microleakage in Obturated Root Canals: An In Vitro Study. J Endod 1991;17:324-31.

42. Siqueira JF, Rocas IN, Lopes HP, and de Uzeda M. Coronal Leakage of Two Root Canal Sealers Containing Calcium Hydroxide after Exposure to Human Saliva. J Endod 1999; 25:14-6.

43. Difco and BBL Manual, $2^{\text {nd }}$ Edition. http://www.bd.com/europe/regulatory/Assets/IFU/Difco_BBL/222810.pdf

44. Sedgley C, Applegate B, Nagel A, and Hall D. Real-Time Imaging and Quantification of Bioluminescent Bacteria in Root Canals In Vitro. J Endod 2004;30:893-8.

45. Heitzer A, Applegate B, Kehrmayer S, et al. Physiological considerations of environmental applications of lux reporter fusions. J Microbiol Methods 1998;31:45-57.

46. Francis KP, Yu J, Bellinger-Kawahara C, et al. Visualizing pneumococcal infections in the lungs of live mice using bioluminescent Streptococcus pneumoniae transformed with a novel Gram-positive lux transposon. Infect Immun 2001;69:3350-8.

47. Molander A, Reit C, Dahlen G, Kvist T. Microbiological status of root filled teeth with apical periodontitis. Int Endod J 1998;31:1-7.

48. Mindere A, Kundzina R, Nikolajeva V, Eze D, and Petrina Z. Microflora of root filled teeth with apical periodontitis in Latvian patients. Stomatologija, Baltic Dental and Maxillofacial Journal 2010;12:116-21.

49. Harris LG, Foster SJ, and Richards RG. An Introduction to Staphylococcus Aureus, and Techniques for Identifying and Quantifying S. aureus Adhesins in Relation to Adhesion to Biomaterials: Review. European Cells and Materials 2002;4:39-60.

50. Staphylococcus aureus ATCC 49525 (Xen36) Technical Data Sheet. Perkin Elmer. 2015. 
51. Skinner RL, Himel VT. The sealing ability of injection-molded thermoplasticized guttapercha with and without the use of sealers. J Endod 1987;13:315.

52. Wu MK, Wesselink PR. A primary observation on the preparation and obturation of oval canals. Int Endod J 2001;34:137-41.

53. De-Deus G, Coutinho-Filho T, Reis C, Murad C, Paciornik S. Polymicrobial leakage of four root canal sealers at two different thicknesses. J Endod 2006;32:998-1001.

54. Shokouhinejad N, Gorjestani H, Nasseh AA, Hoseini A, Mohammadi M and Shamshiri AR. Push-out bond strength of gutta-percha with a new bioceramic sealer in the presence or absence of smear layer. Aust Endod J 2013;39:102-106.

55. Sagsen B, Ustun Y, Demirbuga S et al. Push-out bond strength of two new calcium silicate-based endodontic sealers to root canal dentine. Int Endod J 2011;44:1088-91.

56. Carvalho NK, Prado MC, Senna PM, et al. Do smear-layer removal agents affect the push-out bond strength of calcium silicate-based endodontic sealers? Int Endod J 2017;50:612-19.

57. Sarkar NK, Caicedo R, Ritwik P, Moiseyeva R and Kawashima I. Physicochemical Basis of the Biologic Properties of Mineral Trioxide Aggregate. J Endod 2005;31(2):97-100.

58. Hammad M, Qualtrough A, and Silikas N. Extended Setting Shrinkage Behavior of Endodontic Sealers. J Endod 2008;34(1):90-93.

59. Bergenholtz G, Spångberg L. Controversies in Endodontics. Crit Rev Oral Biol Med 2004;15:99-114. 


\section{Appendix}

Data collection for statistical analysis. Treatment 1 - EndoSequence BC Sealer, Treatment 2 ThermaSeal Plus Ribbon Sealer, Treatment 3 - GuttaFlow 2. Status 1 - Complete bacterial leakage, Status 0 - No bacterial leakage.

\begin{tabular}{|c|c|c|c|}
\hline Tooth & Treatment & Time_Days & Status \\
\hline 1 & 1 & 2 & 1 \\
\hline 2 & 1 & 7 & 1 \\
\hline 3 & 1 & 43 & 1 \\
\hline 4 & 1 & 1 & 1 \\
\hline 5 & 1 & 8 & 1 \\
\hline 6 & 1 & 50 & 0 \\
\hline 7 & 1 & 1 & 1 \\
\hline 8 & 1 & 45 & 1 \\
\hline 9 & 1 & 50 & 0 \\
\hline 10 & 1 & 1 & 1 \\
\hline 11 & 1 & 50 & 0 \\
\hline 12 & 1 & 8 & 1 \\
\hline 13 & 2 & 29 & 1 \\
\hline 14 & 2 & 28 & 1 \\
\hline 15 & 2 & 3 & 1 \\
\hline 16 & 2 & 15 & 1 \\
\hline 17 & 2 & 1 & 1 \\
\hline 18 & 2 & 8 & 1 \\
\hline 19 & 2 & 1 & 1 \\
\hline 20 & 2 & 15 & 1 \\
\hline 21 & 2 & 47 & 1 \\
\hline 22 & 2 & 50 & 0 \\
\hline 23 & 2 & 1 & 1 \\
\hline 24 & 2 & 1 & 1 \\
\hline 25 & 3 & 2 & 1 \\
\hline 26 & 3 & 2 & 1 \\
\hline 27 & 3 & 16 & 1 \\
\hline 28 & 3 & 1 & 1 \\
\hline 29 & 3 & 50 & 0 \\
\hline 30 & 3 & 26 & 1 \\
\hline 31 & 3 & 50 & 0 \\
\hline 32 & 3 & 34 & 1 \\
\hline 33 & 3 & 1 & 1 \\
\hline 34 & 3 & 50 & 0 \\
\hline 35 & 3 & 1 & 1 \\
\hline 36 & 3 & 8 & 1 \\
\hline
\end{tabular}

